\title{
Autoconstrução em contexto de elevação de temperatura: o caso do Cantinho do Céu, São Paulo
}

\author{
Self-construction in a context of rising temperatures: \\ the case of Cantinho do Céu, São Paulo
}

Cristina Kanya Caselli Cavalcanti [I] Angélica Aparecida Tanus Benatti Alvim [II]

\begin{abstract}
Resumo
Este artigo busca identificar os principais elementos da envoltória que prejudicam o desempenho térmico da autoconstrução em um contexto de tendência de elevação das temperaturas, importante efeito da mudança climática. Com base em um conjunto de moradias autoconstruídas, localizadas no Cantinho do Céu, loteamento irregular da zona sul de São Paulo, aplica-se um método de avaliação que combina a análise das envoltórias das habitações, com pesquisa de campo, entrevistas e fotografias termográficas. Os resultados indicam que 0 aquecimento das habitações se relaciona, predominantemente, com o uso inadequado de materiais e a disposição equivocada dos elementos construtivos. Recomenda-se a assessoria técnica como instrumento atuante sobre as deficiências construtivas das habitações precárias, contribuindo para a melhor adaptação da população mais vulnerável aos efeitos do clima.
\end{abstract}

Palavras-chave: mudança climática; aquecimento; autoconstrução; assistência técnica; Cantinho do Céu-São Paulo.

\begin{abstract}
This article seeks to identify the main envelope elements that hinder the thermal performance of self-construction in a context of rising temperatures, an important effect of climate change. Based on a set of self-built houses located in Cantinho do Céu, an irregular settlement in the southern region of São Paulo, we used an evaluation method that combines the analysis of the building envelopes with field research, interviews, and thermographic photographs. The results indicate that the heating of the dwellings is predominantly related to the inappropriate use of materials and to the wrong disposition of construction elements. Technical advice is recommended as a tool that acts on the construction defects of precarious housing, contributing to a better adaptation of the most vulnerable population to climate effects.
\end{abstract}

Keywords: climate change; heating; selfconstruction; technical advice; Cantinho do Céu São Paulo. 


\section{Introdução}

Mudança Climática compreende uma alteração no clima que pode ser identificada por variações incomuns nas médias de temperatura e precipitação, assim como na variabilidade de suas propriedades ou intensidade, persistindo por um período prolongado, de décadas ou mais. Sua origem pode ser natural, ter componentes externos (variação na radiação e alteração na órbita da Terra) ou até mesmo sofrer influência antrópica, como, por exemplo, a alteração na composição da atmosfera ou uso do solo (Field et al., 2012, p. 5). Trata-se de fenômeno que coloca em xeque o desenvolvimento sustentável das cidades, na medida em que estas têm sofrido um aumento da periodicidade de desastres naturais oriundos dos extremos climáticos (Apollaro e Alvim, 2017).

Entre os efeitos da mudança climática estão as oscilações da temperatura. Nos últimos 150 anos, o ritmo de aquecimento está 50 vezes mais acelerado do que foi constatado até então (Nobre, Reid e Veiga, 2012). Estudos sinalizam que o aquecimento global é resultado do aumento de dióxido de carbono orgânico $\left(\mathrm{CO}_{2}\right)$, consequência de atividades humanas que aumentam a concentração de gases de efeito estufa $\left(\mathrm{CO}_{2}\right.$ e $\left.\mathrm{CH}_{4}\right)$ na troposfera, elevando o potencial de retenção de calor da atmosfera e a temperatura do planeta (ibid.).

As oscilações de temperatura provocam, nas cidades, as chamadas "Ilhas de Calor", um fenômeno climático que ocorre a partir da elevação da temperatura de uma área em relação a outra. Nesse contexto, áreas urbanizadas impermeabilizadas podem atingir temperaturas de $27^{\circ} \mathrm{C}$ a $50^{\circ} \mathrm{C}$ maiores do que a temperatura do ar no verão; enquanto superfícies sombreadas ou úmidas permanecem com temperaturas próximas à do ar. Essas superfícies que absorvem e emitem grandes quantidades de calor têm alto impacto na formação das Ilhas de Calor (EPA, 2017). Ou seja, as grandes áreas construídas nas cidades tornam-se baterias de calor, absorvendo grandes quantidades de energia térmica durante o dia e liberando o calor, aos poucos, durante a noite, influindo na temperatura do ar.

0 aumento exponencial da população urbana, ${ }^{1}$ acompanhado do incremento das desigualdades socioespaciais, com ocupação de áreas ambientalmente frágeis por moradias precárias, evidencia os efeitos da mudança climática. Habitantes de assentamentos precários urbanos enfrentam maior exposição ao aquecimento, às intempéries, à poluição e estão mais sujeitos a riscos de saúde (United Nations, 2019).

Especialistas apontam que os efeitos da mudança climática são mais perversos nas populações de baixa renda, especialmente naquelas que vivem em condições precárias. Melhor dizendo, os eventos climáticos têm relação direta com o empobrecimento da população mundial, seja por desastres naturais, seja por origem antrópica (Hallegatte et al., 2016). Hallegatte et al. (ibid.) indicam que mais de $60 \%$ da população mundial ${ }^{2}$ está exposta a riscos constantes advindos das ameaças provenientes dos eventos climáticos. Khoday e Ali (2018) estimam que, em 2030, cerca de 100 milhões de pessoas se encontrará em situação de pobreza extrema, em função dos efeitos perversos dos eventos climáticos. Para Nobre (2011), o risco de ser vítima de um desastre provocado pelo clima aumenta de acordo com a precariedade das condições sociais e rendas mais baixas. Quanto mais vulnerável a população de um território e mais precária a 
infraestrutura urbana e habitacional, mais suscetível a comunidade estará a desastres oriundos do clima.

A qualidade da habitação tem um papel primordial na busca por alternativas para mitigar os efeitos do clima sobre a população. Assentamentos precários, especialmente favelas e loteamentos irregulares, reúnem, de modo geral, habitações com padrões construtivos alheios às normas edilícias que, quando aliadas à ausência de infraestrutura urbana (água e esgoto), potencializam ainda mais os problemas oriundos dos eventos climáticos em sua população. Quase sempre, são modalidades de habitação que expõem seus moradores a inúmeros riscos à saúde, tanto doenças provocadas pelas más condições de vedação ou ventilação, como enfermidades do trato respiratório e cardiovasculares, quanto doenças psiquiátricas potencializadas pela superlotação (WHO, 2018).

No âmbito da ampla gama de pesquisas e políticas públicas que tratam sobre a mudança climática e seu impacto na região da América Latina e Caribe, poucas são aquelas que abordam o tema da habitação precária e os efeitos do aumento de temperatura. De um modo geral, a maioria trata do tema a partir da eficiência energética (McTarnaghan et al., 2016). Pesquisas e políticas públicas deveriam destinar atenção especial para questões de manutenção e gestão do estoque habitacional existente, alocando recursos suficientes para melhoria dos aspectos construtivos e redução dos riscos advindos da mudança climática (Un-Habitat, 2003).
Conhecer as deficiências que tornam as habitações precárias, especialmente as autoconstruídas, modalidade muito comum nas cidades brasileiras, mais suscetíveis a alterações do clima, com enfoque no aquecimento, é o propósito deste artigo. Tal conhecimento pode contribuir com proposições que mitiguem os efeitos do clima em áreas de pobreza. Isto porque, em locais onde não há risco de deslizamento de terra, o aumento da temperatura é um dos principais elementos da mudança climática que interferem na qualidade de vida da população.

Este artigo, parte de pesquisa desenvolvida $^{3}$ com abordagem nas habitações de baixa renda, busca identificar os principais elementos da envoltória que prejudicam o desempenho térmico da autoconstrução em um contexto de tendência de elevação das temperaturas (fenômeno importante da mudança climática). Com base em um conjunto de moradias autoconstruídas, localizadas no Cantinho do Céu, loteamento irregular da zona sul de São Paulo, aplica-se um método de avaliação que combina a análise das envoltórias das habitações, com pesquisa de campo, entrevistas e fotografias termográficas.

Como parte das conclusões, e sem esgotar a complexidade do tema, propõe-se que é fundamental ampliar o papel da arquitetura via assistência técnica para a população de baixa renda, indicando que melhorias habitacionais devem ter foco na adaptação ao clima, promovendo conforto, saúde e eficiência energética nas habitações autoconstruídas. 


\section{Mudança climática, autoconstrução e o papel da assistência técnica}

\author{
Mudança climática \\ e aspectos construtivos
}

Os efeitos da mudança climática vêm deturpando o que se conhecia sobre o clima da cidade de São Paulo e de grande parte de sua área metropolitana, que tem apresentado uma tendência de noites mais quentes em relação ao passado (Oliveira e Alves, 2011). Nos últimos anos, São Paulo sofre com chuvas intensas, ondas de calor e longos períodos de estiagem. Os efeitos são perversos: enchentes, secas, excesso de calor e poluição.

Nobre (2011) reforça que existe uma relação direta entre a ocupação do solo urbano e o processo de urbanização de São Paulo que afeta e tem sido afetada pelos extremos climáticos, como chuvas intensas e aumento de temperatura. Medições feitas pela USP e pelo CGE (Centro de Gerenciamento de Emergências) demonstram que as áreas altamente impermeabilizadas na cidade, ou seja, densamente construídas e pavimentadas, colaboram com a formação de tempestades de curta duração e alta intensidade e, por sua vez, elas são as que mais sofrem com as enchentes e inundações. Além da questão das chuvas intensas, essas áreas densamente construídas armazenam grandes quantidades de calor durante 0 dia, liberando-o, aos poucos, durante a noite, influindo na temperatura do ar.

O Quadro 1 apresenta os três principais eventos advindos da mudança climática que são recorrentes em São Paulo e as consequências de cada um para a população e para o ambiente construído. Merecem destaque a influência das características térmicas dos materiais da envoltória e as dimensões das aberturas no conforto dos moradores e no consumo energético das habitações.

Sob o ponto de vista construtivo, a OMS (Organização Mundial da Saúde) reforça a necessidade de proteção da população em relação a eventos extremos do clima como aspecto primordial para garantir a resiliência (WHO, 2018). Os efeitos adversos do clima têm demonstrado de forma veemente a importância da habitação como abrigo para proteção das intempéries. A habitação ganha papel central no debate, pois possibilita que o ser humano exerça suas necessidades fisiológicas básicas, como dormir, alimentar-se e proteger-se dos perigos externos. A qualidade da habitação tem relação direta com o grau de exposição dos moradores em relação ao clima. Quanto mais precária uma moradia, menor o poder de proteção dos seus ocupantes.

No âmbito deste artigo, evoca-se a necessidade de considerar os aspectos do conforto térmico para o desempenho energético da edificação, especialmente porque, na autoconstrução, modalidade habitacional objeto desta pesquisa, o aquecimento é um dos problemas mais recorrentes. 0 conforto térmico é um aspecto relevante para a satisfação e a saúde do morador; este influencia no consumo energético necessário para condicionar mecanicamente o ambiente (Roaf, Crichton e Nicol, 2009). O conhecimento sobre características térmicas dos materiais construtivos, como a capacidade e a velocidade de transmissão de calor, absortância, assim como resistência térmica, orientação de aberturas ao sol e ventos dominantes, são fundamentais para minimizar os efeitos adversos do clima. As informações 
Quadro 1 - Síntese dos efeitos da mudança climática no estado de São Paulo e os efeitos sobre a construção habitacional e seus ocupantes

\begin{tabular}{|c|c|c|}
\hline $\begin{array}{l}\text { Mudança } \\
\text { climática }\end{array}$ & Consequências para a população & Efeitos na construção \\
\hline Calor intenso & $\begin{array}{l}\text { - Aumento da demanda por refrigeração } \\
\text { - Redução da qualidade de vida da } \\
\text { população, em decorrência da inadequação } \\
\text { das moradias } \\
\text { - Maior impacto sobre população de risco } \\
\text { (idosos, bebês e pobres) } \\
\text { - Queda na qualidade do ar }\end{array}$ & $\begin{array}{l}\text { - Características térmicas da alvenaria } \\
\text { - Caixilhos (posicionamento, vedação e } \\
\text { dimensionamento) } \\
\text { - Características térmicas da cobertura }\end{array}$ \\
\hline Seca & $\begin{array}{l}\text { - Falta de água para abastecimento da } \\
\text { população e para atividades econômicas } \\
\text { - Redução do potencial de geração de } \\
\text { eletricidade } \\
\text { - Aumento do fluxo migratório }\end{array}$ & $\begin{array}{l}\text { - Equipamentos economizadores de água } \\
\text { - Coleta de água da chuva } \\
\text { - Reuso de água cinza } \\
\text { - Uso de biodigestor para tratar esgoto } \\
\text { - Áreas impermeáveis interferem no ciclo hídrico, } \\
\text { dificultando a manutenção dos níveis de corpos } \\
\text { d'água; } \\
\text { - A economia do uso de água no âmbito } \\
\text { doméstico pode auxiliar na manutenção dos níveis } \\
\text { dos reservatórios; } \\
\text { - Sem vínculo direto com a construção, mas as } \\
\text { vulnerabilidades acentuadas por ela pode ser um } \\
\text { dos condicionantes das migrações; }\end{array}$ \\
\hline $\begin{array}{l}\text { Precipitações } \\
\text { abundantes }\end{array}$ & $\begin{array}{l}\text { - Aumento na frequência e intensidade das } \\
\text { precipitações, enchentes e inundações }\end{array}$ & $\begin{array}{l}\text { - Estanqueidade da cobertura } \\
\text { - Estabilidade da cobertura } \\
\text { - Resistência dos materiais de cobertura a chuvas } \\
\text { e ventos }\end{array}$ \\
\hline
\end{tabular}

Fonte: Oliveira e Alves (2011). Elaborado pelas autoras.

sobre os elementos construtivos, aliadas à capacidade humana de administrar o calor, seja com mecanismos termorreguladores do organismo, seja com equipamentos de condicionamento de ar, mostram se a edificação é ou não minimamente confortável. ${ }^{4}$

Nas cidades brasileiras, é evidente que existe uma relação desigual entre clima e construção que interfere na qualidade de vida dos moradores, especialmente quando se trata de habitação precária.

\section{Autoconstrução e o papel da assistência técnica}

A realidade da autoconstrução é parte dominante do cenário das cidades brasileiras, independentemente da faixa de renda. Segundo pesquisa inédita realizada em 2015 pelo Conselho de Arquitetura e Urbanismo (CAU), ${ }^{5}$ em parceria com o Instituto Datafolha, com 2.419 pessoas em todo o Brasil, $54 \%$ da população economicamente ativa já construiu 
ou reformou imóvel residencial ou comercial. Desse conjunto, $85 \%$ fizeram o serviço por conta própria, sem a contratação de profissional habilitado.

Completamente alheia a códigos de obras ou a qualquer tipo de projeto, a autoconstrução tem o objetivo de atender às necessidades de moradia da população de baixa renda (Sampaio, 1990), sendo a única arquitetura que pode ser consumida por essa importante parcela da população brasileira (Maricato, 1979). Como não tem um projeto, trata-se de uma modalidade construtiva fruto da criatividade dos seus proprietários, que não seguem padrões preestabelecidos em normas de desempenho, códigos de obras e leis de zoneamento. Esse tipo de habitação alia-se, na maioria das vezes, à irregularidade na posse da terra, com o desrespeito às leis edilícias (Caldeira, 2017). Segundo Baltazar (2012), a ilegalidade não está em construir, mas sim em fazê-lo sem alvarás e projetos aprovados, ignorando leis de uso do solo e códigos de obras, impossibilitando a obtenção do auto de conclusão de obra, conhecido como habite-se. Em geral, são habitações que envolvem muitas improvisações e bricolagens, mas que representam o sonho do morador em buscar uma casa cada vez melhor (Caldeira, 2017).

A autoconstrução exige um grande consumo de materiais, que costumam ser adquiridos em etapas, principalmente pela dificuldade de acesso ao crédito. Financiamentos raramente são concedidos por instituições financeiras em decorrência da falta de documentos relativos ao terreno e da comprovação de renda dos potenciais financiados. Muitas vezes, depósitos de materiais acabam fazendo o papel de credor, emprestando dinheiro a juros muito acima dos praticados pelo mercado
(Caldeira, 2017; Maricato, 1979). Caldeira (2017) ressalta, ainda, que tudo isso acontece em um mercado paralelo, especializado nas necessidades da população de baixa renda, moradores dos assentamentos irregulares ou precários, além da lógica oficial.

Os efeitos da mudança climática, especialmente o aumento da temperatura, são perceptíveis principalmente na envoltória da habitação autoconstruída, isto é, nas paredes externas, janelas, coberturas e pisos. 0 aumento do calor aliado ao mau uso dos materiais construtivos na maioria das construções de baixa renda afetam, de um modo geral, o conforto térmico da habitação, aspecto relevante para a satisfação e saúde do morador (Roaf, Crichton, Nicol, 2009).

A relação desfavorável entre clima e construção, principalmente em função da precariedade, é um indicativo da necessidade de atuação do poder público com políticas de incentivo à melhoria habitacional. O Plano Nacional sobre Mudança do Clima cita a importância de melhorar a qualidade da habitação como forma de mitigar os efeitos da mudança climática, aumentando sua adaptabilidade.

Mas como melhorar efetivamente a habitabilidade de moradias que abrigam população que não tem recursos financeiros e/ou acesso a financiamentos?

A assistência técnica para melhoria habitacional, instrumento criado pela lei federal $n$. 11.888/2008 (Lei da Assistência Técnica), pode contribuir para minimizar parte dos problemas. A proposta consiste na disponibilização de assistência técnica a cargo de profissionais das áreas de arquitetura e engenharia para apoio especializado à população (urbana ou rural) com faixa de renda de até 3 salários mínimos. Segundo a Lei, a União, os estados, o Distrito 
Federal e os municípios devem garantir o direito à assistência técnica pública e gratuita para o projeto, à construção de habitação de interesse social, à manutenção e à reforma da moradia precária dessa parcela da população. Infelizmente, durante os 12 anos que separam a promulgação da lei e os dias de hoje, o seu alcance ainda é ínfimo. ${ }^{6}$

No contexto de São Paulo, se de fato tal legislação fosse incorporada à política pública habitacional, ela poderia contribuir com a produção ou adaptação de moradias autoconstruídas com materiais e técnicas que minimizassem os impactos do calor, da seca e das precipitações, efeitos mais perceptíveis em decorrência da mudança climática.

Sem pretender dar conta da amplitude do tema, a pesquisa, apresentada a seguir, visa a contribuir com o debate acerca da habitação precária, especialmente a autoconstrução em um contexto de mudança climática.

\section{A pesquisa}

\section{O método}

O método de avaliação aplicado ao estudo de caso do loteamento irregular conhecido como Cantinho Céu, localizado na área de proteção de mananciais da sub-bacia Billings, zona sul de São Paulo, divide-se em três partes:

a) Pesquisa de campo

A pesquisa de campo envolveu o levantamento fotográfico e a aplicação de um questionário ${ }^{7}$ em um universo de 32 moradias, cujo critério de escolha será exposto mais adiante. 0 questionário aplicado reuniu perguntas quantitativas e qualitativas.
As perguntas quantitativas buscaram mensurar os seguintes dados: tipo de vínculo do proprietário com a construção - inquilino ou proprietário - e o tempo de moradia; número de cômodos, número de janelas, existência de cômodos sem aberturas; ocorrência de doenças respiratórias ou cardiovasculares entre os moradores; existência de mofo, umidade e pó; gastos com água e eletricidade; e se o calor era um aspecto problemático.

As qualitativas voltaram-se para o entendimento da rotina da casa em relação à limpeza, se o local era apreciado pelos moradores; a identificação dos pontos positivos e negativos da habitação e o que podia ser melhorado; reclamações dos demais moradores; e, por fim, se viam nos problemas de saúde relações com as condições das casas.

As visitas às moradias, realizadas durante a aplicação dos questionários, permitiu que fossem feitas vistorias das condições das construções, assim como levantamento fotográfico. Em 13 habitações, com autorização dos moradores, foram conferidas as medidas dos espaços para que fosse possível detalhar a análise dos elementos projetuais da construção.

b) Análise das envoltórias

Visando à avaliação do impacto do calor, foram verificados os elementos da envoltória das casas, que atuam como uma barreira de proteção aos ocupantes (fachadas, aberturas e coberturas), a saber: os materiais de vedação que compõem as fachadas, assim como seu revestimento; tipos de coberturas e existência ou não de forro; e, por fim, o posicionamento e as dimensões das aberturas das moradias.

Os materiais da envoltória (alvenaria, cobertura e aberturas) foram analisados de acordo com as diretrizes da norma n. 15.220 Desempenho Térmico das Edificações ${ }^{8}$ para a 
Quadro 2 - Síntese dos parâmetros da norma n. 15.220 e RTQ-R

\begin{tabular}{|c|c|c|c|c|}
\hline $\begin{array}{c}\text { Zona } \\
\text { bioclimática }\end{array}$ & Componente & $\begin{array}{l}\text { Absortância solar } \\
\text { (adimensional) }\end{array}$ & $\begin{array}{l}\text { Transmitância térmica } \\
\qquad \mathrm{W} /\left(\mathrm{m}^{2} \mathrm{~K}\right)\end{array}$ & $\begin{array}{l}\text { Capacidade térmica } \\
\qquad \mathrm{KJ}\left(\mathrm{m}^{2} \mathrm{~K}\right)\end{array}$ \\
\hline \multirow{5}{*}{ ZB 3} & Parede & $\begin{array}{l}\alpha \leq 0,6 \\
\alpha>0,6\end{array}$ & $\begin{array}{l}U \leq 3,70 \\
U \leq 2,50\end{array}$ & $\begin{array}{l}\geq 130 \\
\geq 130\end{array}$ \\
\hline & Cobertura & $\begin{array}{l}\alpha \leq 0,6 \\
\alpha>0,6\end{array}$ & $\begin{array}{l}U \leq 2,30 \\
U \leq 1,50\end{array}$ & $\begin{array}{l}\text { sem exigência } \\
\text { sem exigência }\end{array}$ \\
\hline & \multirow{3}{*}{ Abertura } & & & área útil do ambiente $(\mathrm{A})$ \\
\hline & & \multicolumn{2}{|c|}{ aberturas médias para ventilação } & $A \geq 8 \%$ \\
\hline & & \multicolumn{2}{|c|}{ permitir o sol no inverno } & $A \geq 12 \%$ \\
\hline
\end{tabular}

Fonte: elaborado pelas autoras a partir da NBR n. 15.220.

Zona $3^{9}$ e Regulamento Técnico da Qualidade (RTQ-R) para o Nível de Eficiência Energética de Edificações Residenciais (Eletrobras/Procel, 2015), como sintetizado no Quadro 2. Foram elaboradas tabelas para mostrar a transmitância térmica, atraso térmico e resistência térmica de fachadas e coberturas a partir da calculadora de propriedades disponível na plataforma Projeteee - Projetando Edificações Energeticamente Eficientes. ${ }^{10}$ As aberturas foram avaliadas em função do seu dimensionamento e área útil para ventilação e iluminação natural.

c) Tratamento dos dados

Os dados resultantes das duas etapas anteriores foram avaliados e permitiram a separação de categorias de análise em relação ao calor, sendo possível verificar as fragilidades dessas habitações em relação a temperaturas elevadas.

Nas visitas de campo, foram avaliados o tipo e a constituição da alvenaria e da cobertura, sob parâmetros térmicos da norma n. 15.220, e a quantidade de aberturas. Os dados coletados em campo, no que concerne tanto à forma da habitação, quanto às características térmicas dos sistemas empregados, foram tabulados (desempenho térmico) e relacionados com aspectos apontados como produtos da mudança climática em São Paulo, calor intenso, secas e precipitações abundantes. A partir dessa relação com o clima, foram separados elementos de análise para classificar as habitações de acordo com os problemas construtivos que geravam inadequações quanto à proteção ao calor. Em seguida, elaborou-se uma matriz na qual foi possível identificar um padrão de deficiências recorrentes, balizado pela norma n. 15.220, resultando em um diagnóstico da situação atual. 0 gráfico solar e as fotografias termográficas foram utilizados nas três piores casas para corroborar as conclusões feitas a partir do diagnóstico das deficiências.

Durante as visitas, por um lado, constatou-se que as alvenarias estavam protegidas do calor em função da proximidade das casas, e consequente sombreamento das superfícies, e, por outro, coberturas mostraram inadequações em relação a suas características térmicas e aberturas em relação ao posicionamento. 
Por fim, as 32 casas foram classificadas em função de elementos construtivos que demonstram a capacidade de a envoltória proteger o interior do calor: laje sem telhado; telhado de fibrocimento; janelas voltadas a corredores estreitos; ambientes sem abertura para o exterior; cômodos sem aberturas; e aberturas na mesma face. Aqui foram combinados elementos sobre aspectos térmicos comparados com parâmetros da NBR n. 15.220 e questões sobre o posicionamento das aberturas. As três casas com os piores resultados foram fotografadas com câmera termográfica para verificar as temperaturas dos materiais empregados e confirmar o impacto das deficiências. Os resultados permitem verificar os principais problemas do universo de habitações pesquisado em relação ao uso de materiais e sistemas construtivos inadequados ao clima local, que prejudica o condicionamento passivo e a iluminação natural da autoconstrução.

\section{O estudo de caso e aplicação do método}

Loteamentos irregulares brasileiros são majoritariamente constituídos de habitações autoconstruídas (com ou sem autogestão), sem projeto e executados com escassos recursos financeiros e técnicos. A pesquisa em questão centrou-se em estudar habitações autoconstruídas em uma península da represa Billings, na região conhecida como Cantinho do Céu, formada pelos loteamentos irregulares: Cantinho do Céu, Residencial dos Lagos, Gaivotas e Eucaliptos.

A escolha desse conjunto de loteamentos para o estudo de caso justifica-se por diversos fatores. Trata-se de uma região situada em área de proteção e recuperação de mananciais, portanto ambientalmente frágil, e que reúne altos índices de vulnerabilidade social; é objeto de políticas públicas urbana e ambiental; e vem sendo estudada pelas pesquisadoras há alguns anos. Como está perto da represa, não deveria ser uma região que sofre forte impacto do aquecimento; porém a ocupação irregular desconsiderou seus atributos naturais, impermeabilizando grande parte da península. Suas moradias, a maioria autoconstruída, reproduzem o padrão construtivo das periferias da cidade.

Foram pesquisadas 32 habitações, visando a alcançar relevância estatística: ${ }^{11} 14$ habitações no Residencial dos Lagos; 11, no loteamento Cantinho do Céu; 5 no Gaivotas; e 2 no Eucaliptos (Figura 1).

A área de estudo reúne 42 setores censitários do IBGE; 71,4\% do seu território possui um Índice Paulista de Vulnerabilidade Social (IPVS) ${ }^{12}$ classificado como muito alto (IPVS 6), e 9,5\% como alto (IPVS 5); a população é de, aproximadamente, 36.610 habitantes, e sua renda média, produto da soma de todos os setores censitários que compõem a área de estudo, é de $\mathrm{R} \$ 453,20$ per capita (Prefeitura Municipal de São Paulo, 2019).

Conforme a lei estadual n. 13.579/2009, que define a Área de Proteção e Recuperação dos Mananciais da Bacia Billings, a região insere-se em Subárea de Ocupação Dirigida, com o trecho mais precário definido como Área de Recuperação Ambiental (ARA tipo 1). ${ }^{13}$ No âmbito do Plano Municipal de Habitação de 2010 (PMH, 2010), esse conjunto de loteamentos foi indicado, pelo poder público municipal, como área prioritária de intervenção, por reunir cenário de alta vulnerabilidade, principalmente em decorrência da presença de moradias 
Figura 1 - Mapa de localização dos loteamentos irregulares da área de estudo

\section{LOCALIZAÇÃO DO CANTINHO DO CÉU}

Região Metropolitana de São Paulo e Bacia Hidrográfica do Alto Tietê

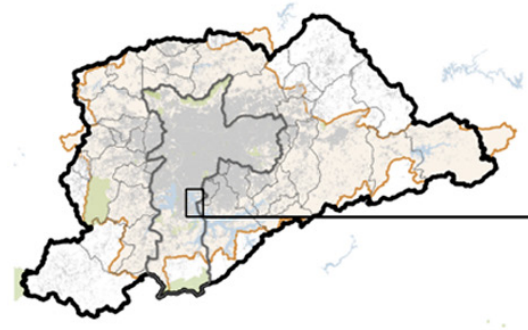

Região Metropolitana de São Paulo (RMSP) Municípios RMSP

Bacia Hidrográfica do Alto Tietê

Mancha urbana

Parques

Corpos d'água

Área de risco geotécnico

Loteamento irregular

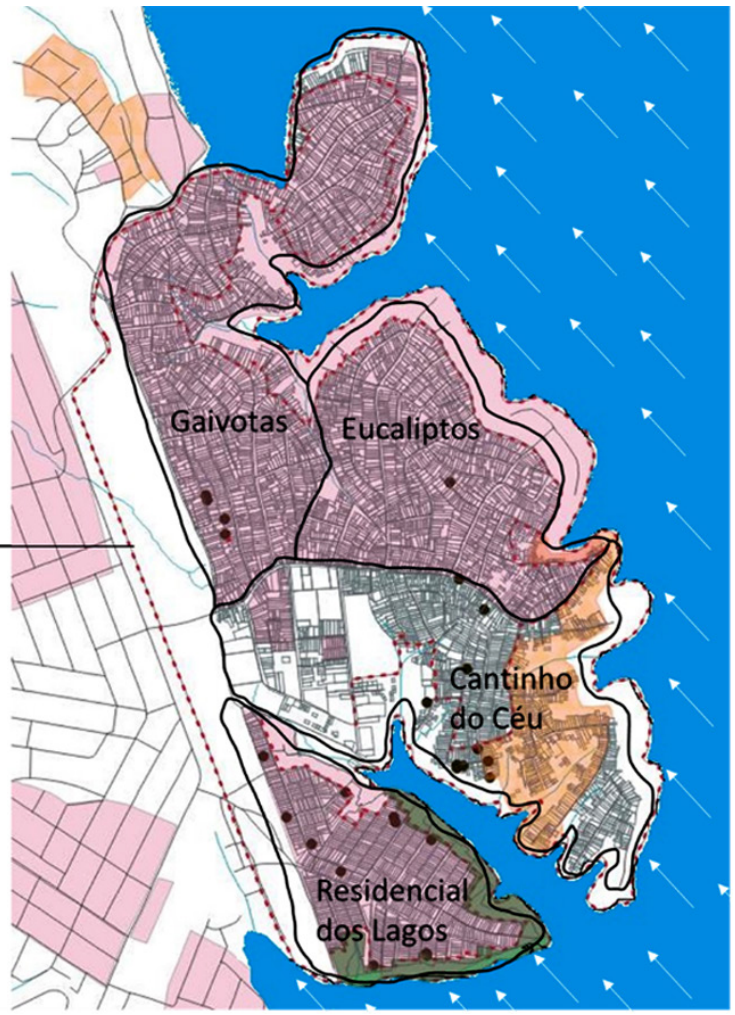

Legenda: as flechas em branco apontam a direção dominante dos ventos a partir dos dados do site Windfinder (https://pt.windfinder.com/\#12/-23.7148/-46.5638. Acesso em: 31 out 2019).

Fonte: mapa elaborado pelas autoras com base em França e Barda (2012), Miranda (2003) e Geosampa (PMSP, 2019).

construídas fora dos padrões edilícios e inseridas em área ambientalmente protegida.

Ao longo dos anos de 1990, a região foi objeto de melhorias parciais na infraestrutura, com a ligação dos domicílios, primeiro, à rede de energia, em 1992, e depois, em 1995, à rede de água (Matsunaga, 2015). Entre os anos de 2008 e 2012, parte do conjunto foi objeto de um projeto de urbanização, recebendo melhorias no sistema viário e novas vias, redes de água, esgoto e drenagem; o trecho correspondente ao loteamento Residencial dos Lagos foi considerado piloto para a implantação do Parque Linear Cantinho do Céu, projeto desenvolvido pelo escritório Boldarini Arquitetos Associados (Alvim, 2011; França e Barda, 2012). ${ }^{14}$

Apesar da urbanização no Residencial dos Lagos não ter tido como foco direto à meIhoria das habitações, é evidente que a implantação da infraestrutura de saneamento ambiental (água, esgoto e drenagem), a melhoria 
no sistema viário e, principalmente, a implantação de um sistema de espaços públicos no Parque Linear Cantinho do Céu estimularam melhorias em muitas habitações. Durante diligências realizadas na pesquisa de campo, foram observadas inúmeras obras nos lotes. Muitas das habitações visitadas nesse trecho estavam sendo reformadas, foram reformadas nos últimos anos ou iriam ser reformadas em breve, conforme declaração dos moradores durante as entrevistas.

A escolha das habitações pesquisadas teve auxílio dos agentes sociais ${ }^{15}$ dos loteamentos Cantinho do Céu e Residencial dos Lagos, o que foi determinante para a escolha de quais seriam aprofundadas com a aplicação do método.

Do conjunto de 42 setores censitários que compõem a área de estudo, foram pesquisadas habitações em 10 setores, que possuem características diversas de renda e vulnerabilidade. 0 Quadro 3 apresenta a renda per capita, o número de habitantes, o IPVS dos setores visitados, bem como a relação das habitações pesquisadas (indicando a numeração da pesquisa). Do conjunto de 32 habitações pesquisadas, oito habitações localizam-se em setores com IPVS 6, ou seja, alta vulnerabilidade com presença de aglomerados subnormais; desse subconjunto, duas (as de número 25 e 26) estão em setor com renda média per capita de $\mathrm{R} \$ 371,79$, o segundo setor com menor renda do loteamento. Do lado oposto, apenas uma habitação (12) está situada em setor com IPVS 3, correspondendo à vulnerabilidade mais baixa e renda per capita de $\mathrm{R} \$ 583,50$.

Quadro 3 - Características socioeconômicas da área de estudo e localização das casas pesquisadas

\begin{tabular}{|l|c|c|c|l|}
\hline \multirow{2}{*}{ Setor Censitário } & Renda R\$̦ & População & Vulnerabilidade & \multicolumn{1}{|c|}{ Número das casas } \\
\cline { 2 - 4 } & Per capita (2010) & Habitantes (2010) & IPVS (2010) & \\
\hline 355030830000132 & 444,84 & 1.079 & 4 & 6 \\
355030830000200 & 493,99 & 1.033 & 6 & $5,7,8,9,10$ \\
355030830000203 & 490,84 & 858 & 6 & 1 \\
355030830000243 & 564,30 & 1.210 & 5 & $2,11,15$ \\
355030830000273 & 488,97 & 380 & 4 & 31 \\
355030830000274 & 567,96 & 1.080 & 5 & $3,4,13,14,27,28,29,30,31,32$ \\
355030830000294 & $\mathbf{3 7 1 , 7 9}$ & 564 & 6 & 25,26 \\
355030830000385 & 461,17 & 622 & 4 & $16,17,18,19,21,22,23,24$ \\
355030830000386 & 466,47 & 1.115 & 6 & 20 \\
355030830000420 & $\mathbf{5 8 3 , 5 0}$ & 768 & 3 & 12 \\
\hline
\end{tabular}

Fonte: elaborado pelas autoras com base nos dados do Censo do IBGE (2010), Fundação Seade (2010) e no mapa de Indicadores Sociais do Geosampa (PMSP, 2019). 


\section{Resultados}

A aplicação do método permitiu aferir alguns importantes resultados.

Em relação às características construtivas das habitações pesquisadas, foram analisados os tipos dos materiais empregados, o dimensionamento e posicionamento dos caixilhos, as patologias e características térmicas dos materiais utilizados em relação à NBR n. 15.220.

A vedação empregada nas habitações é predominantemente o bloco cerâmico furado (tijolo baiano de 6 furos). Apenas uma casa visitada no Cantinho do Céu foi construída em bloco de concreto, sem acabamento externo nem interno, deixando o bloco aparente. 0 acabamento externo, quando existe, é de massa fina com ou sem pintura, ocasionalmente massa corrida e pintura. Do conjunto, cinco casas não possuem acabamento em todas as paredes externas. Internamente a maioria das casas tem acabamento em argamassa, massa corrida ou massa fina e pintura. Apenas duas casas apresentam vedações compostas por blocos aparentes externamente e internamente: a casa 6 (bloco de concreto) e a casa 10 (bloco cerâmico).

A cobertura varia entre laje pré-moldada (tipo H8), muitas vezes sem impermeabilização, e telhado de fibrocimento. Existem casos nos quais há combinação de telhado e laje e telhado e forro (PVC ou madeira). O sistema mais recorrente nas habitações visitadas foi laje plana $(37,5 \%)$, seguido por laje coberta com telhado (34,38\%) (Tabela 1).

Os caixilhos são primordialmente de alumínio, adquiridos em lojas de materiais de construção. As medidas mais recorrentes para vitrôs basculantes é de $1,20 \mathrm{~m}$ de largura por $1,0 \mathrm{~m}$ de altura (36,36\% do total pesquisado) e de $1,0 \mathrm{~m} \times 0,60 \mathrm{~m}(18,18 \%)$. As janelas de correr mais comumente utilizadas são de $1,20 \mathrm{~m}$ de largura por $1 \mathrm{~m}$ de altura $(43,48 \%)$ e de $1,5 \mathrm{~m} \mathrm{x}$ $1,0 \mathrm{~m}(17,39 \%)$.

Tabela 1 - Tipos de cobertura das casas pesquisadas

\begin{tabular}{l|c|c}
\hline \multicolumn{1}{c|}{ Tipo de cobertura } & Número de casas & \% de casas \\
\hline Laje & 12 & 37,5 \\
Laje + telha & 11 & 34,38 \\
Laje + pavimento & 1 & 3,13 \\
Telha & 5 & 15,63 \\
Telha + forro & 3 & 9,38 \\
\hline Totais & 32 & 100,00 \\
\hline
\end{tabular}

Fonte: elaborado pelas autoras a partir do levantamento de campo. 
Para permitir a ventilação cruzada, aspecto importante da construção, é necessário que haja aberturas em paredes opostas ou adjacentes. Constatou-se que três das moradias visitadas têm aberturas em apenas uma fachada, e seis delas têm apenas um basculante pequeno em fachada adjacente ou oposta, prejudicando o fluxo de ar.

Uma ventilação natural eficiente, que funcione como condicionamento passivo, requer fatores que dependem da construção propriamente dita, como tamanho e posicionamento das aberturas, assim como sua implantação, mas também de aspectos inerentes ao meio urbano e a direção dos ventos dominantes, no caso do Cantinho do Céu, Sudeste. Löw e Nader (2019) apontam que a ventilação natural interage com os edifícios, e uma ocupação desordenada do solo resulta em velocidades do vento menores, assim como temperaturas no solo mais elevadas, prejudicando o conforto.

Durante as vistorias, pôde-se constatar que a orientação das casas ou suas aberturas não foram feitas em função da trajetória do sol, uma vez que possibilitam a incidência solar no verão e a sombra no inverno, visto que as casas procuraram aproveitar ao máximo o lote. Do conjunto, 23 casas (72\%) apresentam fachadas entre sudeste, sul e sudoeste, que são ensolaradas no verão e sombreadas no inverno, o oposto do indicado para o melhor aproveitamento do condicionamento passivo das construções. Alheias ao sol, as casas acompanham o sentido do terreno, ocupando ao máximo sua área e ignorando recuos de qualquer natureza, resultando em ambientes desprovidos de iluminação natural.

A Figura 2 apresenta um esquema de proximidade em relação ao muro das casas 3 e 4, que são sobrepostas. Nesse caso, no térreo, o corredor tem 1,05m de largura, e, no segundo pavimento, a distância é de aproximadamente $0,60 \mathrm{~m}$. Observa-se, claramente na casa 3, a restrição do acesso à insolação no solstício de verão em função do posicionamento do muro, corredor e fachada com aberturas. No inverno, com alturas mais baixas do sol (ângulos menores de 5ㅇ a 15ㅇ), a insolação atinge apenas o pavimento superior, reduzindo o impacto do aquecimento.

As Figuras 3 e 4 apresentam os gráficos solares relativos, respectivamente, às casas $3 \mathrm{e}$ 4. A mancha verde representa o sombreamento na fachada em que estão quatro aberturas da casa 3 (sala, cozinha, banheiro e dormitório) e duas aberturas da casa 4 (sala/cozinha e dormitório). A mancha roxa representa o sombreamento causado pelo volume da casa. A mancha branca representa o praticamente inexistente acesso ao sol no pavimento térreo e o restrito acesso ao sol no pavimento superior, que no verão pode chegar a três horas e no inverno a menos de 1 hora.

É latente que essa proximidade entre as casas reduz a possibilidade de utilizar o sol como estratégia de aquecimento no inverno; e, no caso específico das casas 3 e 4, permite o excesso de exposição no verão, estratégias equivocadas para um clima com temperaturas ascendentes.

Visando saber se há conformidade ou não do tamanho das aberturas, as áreas de cozinha, dormitório e sala de 13 moradias foram medidas, considerando-se os parâmetros do RTQ-R (Eletrobras/Procel, 2015). A Tabela 2 mostra a relação entre as áreas dos ambientes e as aberturas para ventilação, e a Tabela 3 para iluminação natural. 
Figura 2 - Corte esquemático das casas 3 e 4 e ângulos de altura do sol no solstício de verão

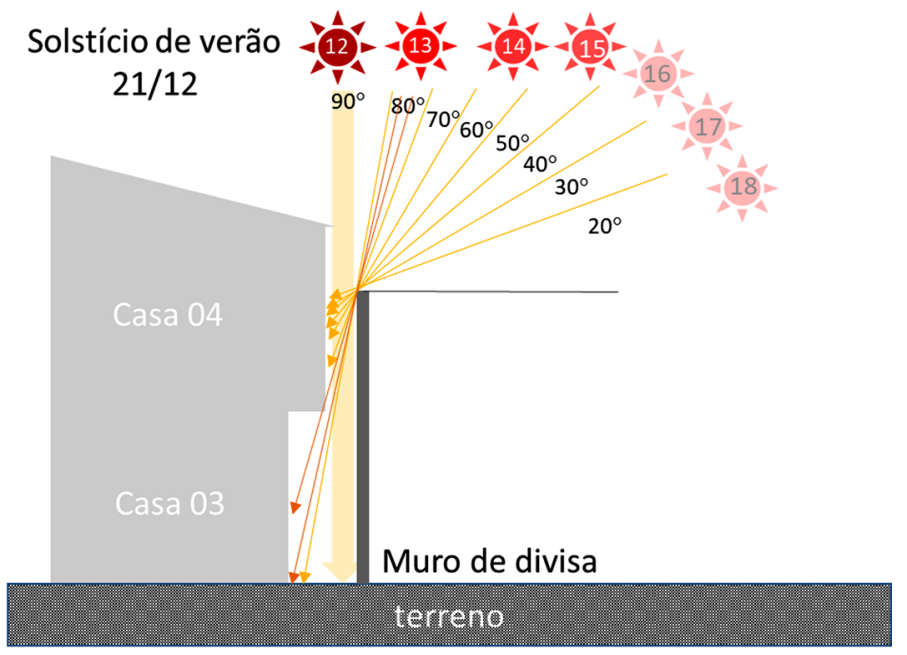

Legenda: a posição das casas e do muro de divisa restringe a incidência da radiação solar no solstício de verão (22/12), data presente no gráfico solar do LabEE, usado como referência para cálculo dos ângulos entre 12 e 18 horas. Fonte: elaborado pelas autoras.

\section{Figura 3 - Gráfico solar para a fachada sudoeste da casa 3}

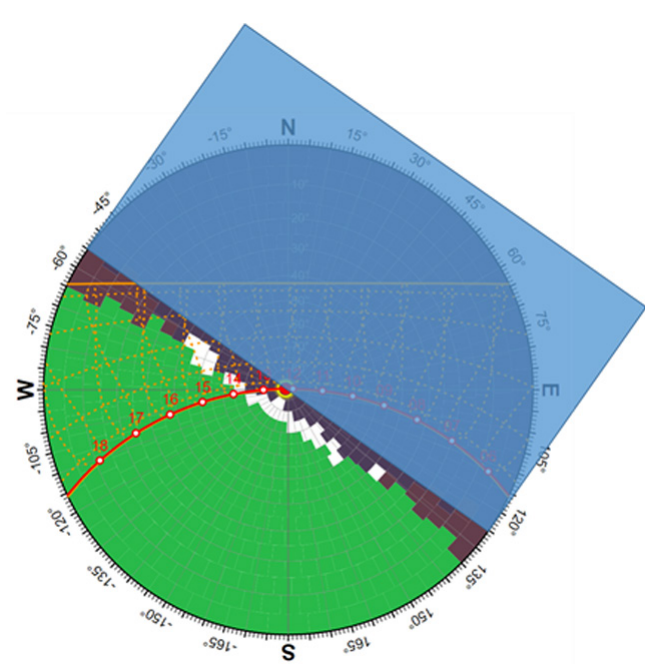

Legenda: o retângulo azul representa o volume da construção, as cores verde e roxa mostram respectivamente a influência do muro e a obstrução da própria construção na fachada do pavimento térreo.

Fonte: gráfico gerado pelo software Dynamic Overshadowing, disponível em: http://andrewmarsh.com/software/shading-box-web/

\section{Figura 4 - Gráfico solar para a fachada sudoeste da casa 4}

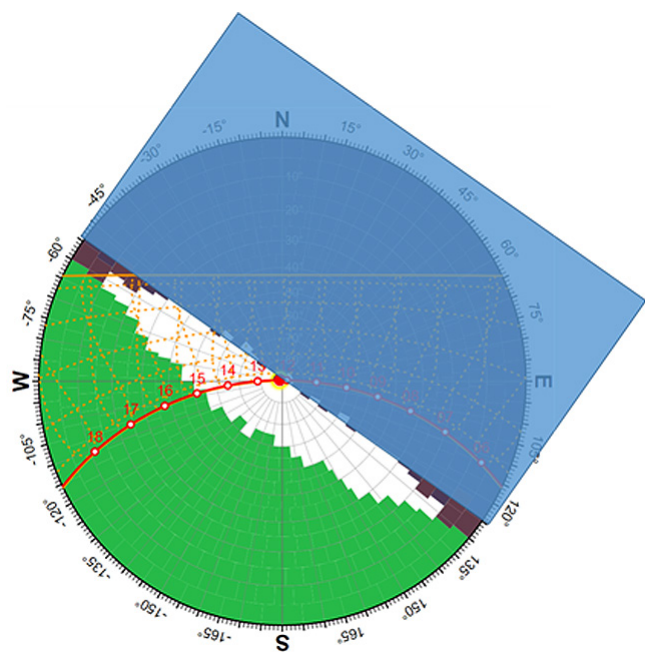

Legenda: o retângulo azul representa o volume da construção, as cores verde e roxa mostram respectivamente a influência do muro e a obstrução da própria construção na fachada do 2o pavimento.

Fonte: gráfico gerado pelo software Dynamic Overshadowing, disponível em: http://andrewmarsh.com/software/shading-box-web/ 
Como se pode observar no Quadro 4, apenas seis ambientes das 13 casas possuíam aberturas adequadas para a ventilação natural. As casas em conformidade com os parâmetros adotados são: 5 e 28 na cozinha; 9, 11 e 14 nas salas; e, por fim, a casa 9 também tinha um dos quartos adequados.

A iluminação natural é ainda mais crítica, visto que a área de abertura deve corresponder a $12,5 \%$ do espaço do ambiente, segundo padrões do Programa Brasileiro de Etiquetagem - PBE Edifica, do Procel (Eletrobras/Procel, 2015). 0 Quadro 5 indica que apenas as casas 9 e 13 tinham aberturas adequadas aos parâmetros de iluminação natural em apenas um dos ambientes: a sala; os demais ambientes estavam em desacordo.
Algumas moradias possuem dormitórios apenas com caixilhos voltados para áreas internas, sem acesso ao exterior, como, por exemplo, vãos de escadas, áreas de serviço e corredores internos; em dois casos, tijolos de vidro ao invés de caixilhos. Trata-se de estratégias usadas para dispor um maior número de cômodos nos espaços exíguos existentes, o que dificulta o acesso ao sol e à ventilação natural.

Expansões e reformas são recorrentes nas habitações em função das necessidades de seus moradores. De modo geral, as ampliações de um ou mais cômodos ocorrem de forma horizontal, ocupando todo o lote, ou verticalmente, sobre as lajes planas que não foram calculadas para suportar tal peso. A maior

Quadro 4 - Avalia as aberturas quanto ao potencial de ventilação natural

\begin{tabular}{|c|c|c|c|c|c|c|c|c|c|c|c|c|c|c|c|}
\hline \multicolumn{16}{|c|}{ VENTILAÇÃO } \\
\hline \multirow[b]{2}{*}{ Casas } & \multicolumn{5}{|c|}{ Cozinha } & \multicolumn{5}{|c|}{ Sala } & \multicolumn{5}{|c|}{ Dormitório } \\
\hline & $\begin{array}{l}\text { Área } \\
\text { de piso }\end{array}$ & $\begin{array}{l}\text { Área } \\
\text { vent. }\end{array}$ & $8 \%$ & Atende? & Externa & $\begin{array}{l}\text { Área } \\
\text { de piso }\end{array}$ & $\begin{array}{l}\text { Área } \\
\text { vent. }\end{array}$ & $8 \%$ & Atende? & Externa & $\begin{array}{l}\text { Área } \\
\text { de piso }\end{array}$ & $\begin{array}{l}\text { Área } \\
\text { vent. }\end{array}$ & $8 \%$ & Atende? & Externa \\
\hline casa 2 & 17,30 & 0,84 & 1,38 & não & sim & 17,97 & 0,60 & 1,20 & não & não & 17,30 & 0,60 & 1,38 & não & $\operatorname{sim}$ \\
\hline casa 3 & 10,05 & 0,76 & 0,80 & não & sim & 13,80 & 0,64 & 1,10 & não & sim & 13,75 & 0,93 & 1,10 & não & não \\
\hline casa 4 & 18,41 & 0,46 & 1,47 & não & sim & \multicolumn{5}{|c|}{ cozinha e sala integradas } & 14,26 & 0,48 & 1,14 & não & $\operatorname{sim}$ \\
\hline casa 5 & 12,45 & 1,36 & 1,00 & $\operatorname{sim}$ & não & 12,59 & 0,71 & 1,01 & não & não & 11,56 & 0,39 & 0,92 & não & $\operatorname{sim}$ \\
\hline casa 7 & 7,76 & 0,45 & 0,62 & não & sim & 12,32 & 0,71 & 0,99 & não & sim & 8,57 & 0,59 & 0,69 & não & $\operatorname{sim}$ \\
\hline casa 8 & 13,38 & 0,81 & 1,07 & não & $\operatorname{sim}$ & \multicolumn{5}{|c|}{ cozinha integrada com a sala } & 13,48 & 0,46 & 1,08 & não & $\operatorname{sim}$ \\
\hline casa 9 & 11,08 & 0,76 & 0,89 & não & não & 10,57 & 1,10 & 0,85 & $\operatorname{sim}$ & sim & 7,88 & 0,73 & 0,63 & sim & não \\
\hline casa 11 & 9,99 & 0,61 & 0,80 & não & não & 12,22 & 1,11 & 0,98 & $\operatorname{sim}$ & $\operatorname{sim}$ & 12,15 & 0,51 & 0,97 & não & não \\
\hline casa 13 & 15,49 & 0,50 & 1,20 & não & sim & 18,52 & 0,00 & 1,20 & não & não & 10,12 & 0,46 & 0,81 & não & $\operatorname{sim}$ \\
\hline casa 14 & 12,13 & 0,95 & 1,20 & não & sim & 9,49 & 1,13 & 0,76 & $\operatorname{sim}$ & não & 14,53 & 1,11 & 1,16 & não & não \\
\hline casa 17 & 11,87 & 0,48 & 0,95 & não & sim & 16,77 & 0,60 & 1,34 & não & $\operatorname{sim}$ & 6,41 & 0,48 & 0,51 & não & $\operatorname{sim}$ \\
\hline casa 18 & 11,21 & 0,70 & 0,90 & não & sim & 10,66 & 0,49 & 0,85 & não & sim & 11,21 & 0,46 & 0,90 & não & $\operatorname{sim}$ \\
\hline casa 22 & 10,27 & 0,00 & 0,82 & não & $\operatorname{sim}$ & 8,31 & 0,48 & 0,66 & não & $\operatorname{sim}$ & 14,20 & 0,42 & 1,14 & não & $\operatorname{sim}$ \\
\hline casa 28 & 7,97 & 0,80 & 0,64 & sim & não & \multicolumn{5}{|c|}{ não tem o ambiente } & 8,44 & 0,60 & 0,68 & não & $\operatorname{sim}$ \\
\hline
\end{tabular}

Fonte: elaborado pelas autoras com base nos levantamentos de campo e parâmetros do Manual do PBEEdifica (Eletrobras/Procel, 2015, p. 8). 
Quadro 5 - Avalia as aberturas quanto ao potencial de iluminação natural

\begin{tabular}{|c|c|c|c|c|c|c|c|c|c|c|c|c|c|c|c|}
\hline \multicolumn{16}{|c|}{ ILUMINAÇÃO NATURAL } \\
\hline \multirow[b]{2}{*}{ Casas } & \multicolumn{5}{|c|}{ Cozinha } & \multicolumn{5}{|c|}{ Sala } & \multicolumn{5}{|c|}{ Dormitório } \\
\hline & $\begin{array}{c}\text { Área } \\
\text { de piso }\end{array}$ & $\begin{array}{c}\text { Área } \\
\text { iluminação }\end{array}$ & $12,5 \%$ & Atende? & Externa & $\begin{array}{c}\text { Área } \\
\text { de piso }\end{array}$ & $\begin{array}{c}\text { Área } \\
\text { iluminação }\end{array}$ & $12,5 \%$ & Atende? & Externa & $\begin{array}{c}\text { Área } \\
\text { de piso }\end{array}$ & $\begin{array}{c}\text { Área } \\
\text { janela }\end{array}$ & $12,5 \%$ & Atende? & Externa \\
\hline casa 2 & 17,30 & 0,78 & 1,88 & não & $\operatorname{sim}$ & 17,97 & 1,05 & 1,88 & não & não & 17,30 & 0,68 & 1,88 & não & $\operatorname{sim}$ \\
\hline casa 3 & 10,05 & 0,73 & 1,26 & não & sim & 13,80 & 1,13 & 1,73 & não & $\operatorname{sim}$ & 13,75 & 1,64 & 1,72 & não & não \\
\hline casa 4 & 18,41 & 0,81 & 2,30 & não & $\operatorname{sim}$ & \multicolumn{5}{|c|}{ cozinha e sala integradas } & 14,26 & 0,54 & 1,78 & não & $\operatorname{sim}$ \\
\hline casa 5 & 12,45 & 1,26 & 1,56 & não & não & 12,59 & 1,22 & 1,57 & não & não & 11,56 & 0,36 & 1,44 & não & $\operatorname{sim}$ \\
\hline casa 7 & 7,76 & 0,42 & 0,97 & não & $\operatorname{sim}$ & 12,32 & 1,03 & 1,54 & não & $\operatorname{sim}$ & 8,57 & 0,66 & 1,07 & não & $\operatorname{sim}$ \\
\hline casa 8 & 13,38 & 0,76 & 1,67 & não & $\operatorname{sim}$ & \multicolumn{5}{|c|}{ cozinha integrada com a sala } & 13,48 & 0,52 & 1,69 & não & $\operatorname{sim}$ \\
\hline casa 9 & 11,08 & 0,71 & 1,39 & não & não & 10,57 & 1,79 & 1,32 & $\operatorname{sim}$ & sim & 7,88 & 0,82 & 0,98 & não & não \\
\hline casa 11 & 9,99 & 0,57 & 1,25 & não & não & 12,22 & 1,11 & 1,53 & não & sim & 12,15 & 1,06 & 1,52 & não & não \\
\hline casa 13 & 15,49 & 0,88 & 1,94 & não & $\operatorname{sim}$ & 18,52 & 2,17 & 2,32 & $\operatorname{sim}$ & não & 10,12 & 0,52 & 1,26 & não & $\operatorname{sim}$ \\
\hline casa 14 & 12,13 & 0,95 & 1,52 & não & $\operatorname{sim}$ & 9,49 & 1,13 & 1,19 & não & não & 14,53 & 1,25 & 1,82 & não & não \\
\hline casa 17 & 11,87 & 0,84 & 1,48 & não & $\operatorname{sim}$ & 16,77 & 1,05 & 2,10 & não & $\operatorname{sim}$ & 6,41 & 0,54 & 0,80 & não & $\operatorname{sim}$ \\
\hline casa 18 & 11,21 & 0,65 & 1,40 & não & $\operatorname{sim}$ & 10,66 & 0,56 & 1,33 & não & sim & 11,21 & 0,51 & 1,40 & não & $\operatorname{sim}$ \\
\hline casa 22 & 10,27 & 0,00 & 1,28 & não & $\operatorname{sim}$ & 8,31 & 0,54 & 1,04 & não & $\operatorname{sim}$ & 14,20 & 0,39 & 1,78 & não & $\operatorname{sim}$ \\
\hline casa 28 & 7,97 & 0,75 & 1,00 & não & não & \multicolumn{5}{|c|}{ não tem o ambiente } & 8,44 & 0,68 & 1,06 & não & $\operatorname{sim}$ \\
\hline
\end{tabular}

Fonte: elaborado pelas autoras com base nos levantamentos de campo e parâmetros do Manual do PBEEdifica (Eletrobras/Procel, 2015, p. 8).

parte das ampliações nas residências visitadas foi feita para dar espaço aos filhos que se casaram e, em algumas ocasiões, como oportunidade de renda (aluguel). As novas coberturas, em geral, são de fibrocimento, material escoIhido pela rapidez e pelo baixo custo.

Para uma melhor compreensão das características térmicas dos materiais utilizados na construção das moradias visitadas, as informações obtidas na pesquisa de campo foram comparadas aos parâmetros da norma NBR n. 15575 com o desempenho térmico em edificações, balizadas pelas orientações de conforto térmico, ${ }^{16}$ especificados no Zoneamento Bioclimático Brasileiro (ABNT-NBR n. 15.220, 2005).
Importante ressaltar que o Zoneamento Bioclimático Brasileiro define diretrizes construtivas para habitações unifamiliares de interesse social e especifica o tamanho e o sombreamento de aberturas, tipos das vedações (paredes e coberturas), estipulando a transmitância térmica e o atraso térmico de referência, além de estratégias para o condicionamento passivo com base na ABNT-NBR n. 15.220 (ibid.). Esse zoneamento dividiu o País em oito zonas a partir de dados climáticos de 1931 a 1990, gerando a Carta Bioclimática de Givoni para o Brasil. ${ }^{17}$

A metrópole de São Paulo está inserida no Zoneamento Bioclimático 3, no qual se recomenda aberturas de dimensões médias 
$(15 \%<A<25 \%)$ com sombreamento no verão e incidência de sol no inverno. A alvenaria recomendada pela Norma n. 15.220 é a leve e refletora, com transmitância térmica menor ou igual a $3,6 \mathrm{~W} / \mathrm{m}^{2} \mathrm{~K}$, e cobertura leve isolada com transmitância menor ou igual a 2,0 W/ $\mathrm{m}^{2} \mathrm{~K}$. Entre as estratégias para o condicionamento térmico passivo, essa mesma norma recomenda, para o verão, a ventilação cruzada e, para o inverno, aquecimento solar da envoltória da edificação e vedações internas pesadas, apostando na inércia térmica.

O Quadro 6 apresenta os dados sobre o desempenho térmico dos sistemas utilizados para coberturas nas moradias visitadas e os parâmetros de referência da NBR para transmitância $(U)$, atraso térmico $(\varphi)$ e capacidade térmica (Ct), de acordo com o especificado para o Zoneamento Bioclimático 3 (ibid.) de São Paulo.

A partir da comparação entre os dados térmicos dos sistemas empregados e os parâmetros da Norma n. 15.220, percebe-se que todos os sistemas empregados nas habitações visitadas são inadequados para as necessidades mínimas de conforto térmico, ou seja, permitem uma penetração de calor maior do que o desejado em função da transmitância superior aos parâmetros da NBR em todos os casos, além de um atraso térmico maior nos exemplos que incluem lajes. A redução da amplitude térmica na cidade de São Paulo, como citado anteriormente, reduz a eficácia da inércia térmica, contribuindo para o superaquecimento de ambientes internos.

Quadro 6 - Elementos construtivos para coberturas e respectivas propriedades térmicas: absortância $(\alpha)$, resistência $(R)$, transmitância térmica $(U)$, atraso térmico $(\varphi)$ e capacidade térmica

\begin{tabular}{|l|c|c|c|c|c|c|c|c|}
\hline \multicolumn{1}{|c|}{ Materiais de cobertura } & $\alpha$ & $\begin{array}{c}\mathbf{R} \\
\left(\mathrm{m}^{2} \mathrm{~K} / \mathrm{W}\right)\end{array}$ & $\begin{array}{c}\mathbf{U} \\
\left(\mathbf{W} / \mathrm{m}^{2} \mathbf{k}\right)\end{array}$ & $\begin{array}{c}\mathbf{U} \\
\mathbf{N B R}\end{array}$ & $\begin{array}{c}\boldsymbol{\varphi} \\
\text { (horas) }\end{array}$ & $\begin{array}{c}\boldsymbol{\varphi} \\
\text { NBR }\end{array}$ & \multicolumn{1}{c|}{$\mathbf{C t}$} & $\begin{array}{c}\mathrm{Ct} \\
\text { NBR }\end{array}$ \\
\hline Telhado de fibrocimento & $0,50^{*}$ & 0,22 & $\mathbf{4 , 6}$ & $\mathrm{U} \leq 2,30$ & $\mathbf{0 , 1}$ & $\leq 3,3$ & 12,8 & $\mathrm{I}$ \\
\hline $\begin{array}{l}\text { Laje pré-moldada com lajota } \\
\text { cerâmica + argamassa inferior }\end{array}$ & $0,65^{* *}$ & 0,35 & $\mathbf{2 , 8}$ & $\mathrm{U} \leq 1,5$ & $\mathbf{5 , 4}$ & $\leq 3,3$ & 204,8 & $\mathrm{I}$ \\
\hline $\begin{array}{l}\text { Telhado de fibrocimento + laje + } \\
\text { argamassa inferior }\end{array}$ & $0,50^{*}$ & 0,38 & $\mathbf{2 , 6}$ & $\mathrm{U} \leq 2,30$ & $\mathbf{4 , 1}$ & $\leq 3,3$ & 247,5 & $\mathrm{I}$ \\
\hline Telhado de fibrocimento + forro & $0,50^{*}$ & 0,36 & $\mathbf{2 , 8}$ & $\mathrm{U} \leq 2,30$ & 0,4 & $\leq 3,3$ & 15,4 & $\mathrm{I}$ \\
\hline
\end{tabular}

Fonte: elaborado pelas autoras com base nos parâmetros da NBR n. 15.220; os dados de $\alpha$ foram extraídos de: *CoeIho, Gomes e Dornelles (2017); ** Norma da ABNT 02:135.07-002 (1998).

Legenda: (I) na coluna Ct NBR significa irrelevante. Os números em vermelhos ressaltam a não conformidade e em verde, conformidade. 
Quadro 7 - Elementos construtivos para vedações e respectivas propriedades térmicas: absortância $(\alpha)$, resistência $(R)$, transmitância térmica $(U)$, atraso térmico $(\varphi)$ e capacidade térmica

\begin{tabular}{|l|c|c|c|c|c|c|c|c|}
\hline \multicolumn{1}{|c|}{ Materiais vedação } & $\alpha$ & $\begin{array}{c}\mathbf{U} \\
\left(\mathbf{W} / \mathbf{m}^{2} \mathbf{k}\right)\end{array}$ & $\begin{array}{c}\mathbf{U} \\
\text { NBR }\end{array}$ & $\begin{array}{c}\mathbf{R} \\
\left(\mathbf{m}^{2} \mathbf{K} / \mathbf{W}\right)\end{array}$ & $\begin{array}{c}\boldsymbol{\varphi} \\
\text { (horas) }\end{array}$ & $\begin{array}{c}\boldsymbol{\varphi} \\
\text { NBR }\end{array}$ & \multicolumn{1}{c|}{$\mathbf{C t}$} & $\begin{array}{c}\mathrm{Ct} \\
\text { NBR }\end{array}$ \\
\hline $\begin{array}{l}\text { Alvenaria acabada, bloco e } \\
\text { argamassa de acabamento cinza }\end{array}$ & $0,30^{* *}$ & 2,4 & $\mathrm{U} \leq 3,7$ & 0,41 & 3,5 & $\leq 4,3$ & 140,3 & $\geq 130$ \\
\hline $\begin{array}{l}\text { Alvenaria acabada, bloco e } \\
\text { argamassa de acabamento } \\
\text { branco }\end{array}$ & $0,158^{* *}$ & 2,4 & $\mathrm{U} \leq 3,7$ & 0,41 & 3,5 & $\leq 4,3$ & 140,3 & $\geq 130$ \\
\hline $\begin{array}{l}\text { Alvenaria com acabamento } \\
\text { interno e sem externamente } \\
\text { (no bloco) }\end{array}$ & $0,65^{* *}$ & 2,6 & $\mathrm{U} \leq 2,5$ & 0,36 & 4,2 & $\leq 4,3$ & 90,3 & $\geq 130$ \\
\hline
\end{tabular}

Fonte: elaborado pelas autoras com base nos parâmetros da NBR n. 15.220; os dados de $\alpha$ foram extraídos de:

** Norma da ABNT 02:135.07-002 (1998).

Legenda: os números em vermelhos ressaltam a não conformidade e em verde, conformidade.

As vedações diferentes das coberturas apresentam propriedades que se enquadram aos parâmetros determinados pelo zoneamento bioclimático no qual se encontram. O Quadro 7 apresenta os dados sobre o desempenho térmico dos sistemas utilizados nas vedações das habitações. Por exemplo, alvenarias sem nenhum tipo de acabamento externo estão um décimo abaixo do estipulado pela norma n. 15.220 (ibid.). Além das paredes apresentarem propriedades térmicas adequadas, em sua maioria, o fato de serem geminadas ou próximas entre si, com corredores que oscilam entre $0,60 \mathrm{~m}$ e $1,30 \mathrm{~m}$, provoca o sombreamento de superfícies das fachadas, como demonstrado nos exemplos das casas 3 e 4 . Isso auxilia na redução do calor, mas pode trazer problemas de umidade pela ausência total de radiação solar.
As Figuras de 5 a 10 indicam alguns dos problemas encontrados de forma recorrente no universo das 32 habitações visitadas. Nas Figuras 5 a 6 , verificam-se os corredores estreitos com insolação restrita, pela pouca largura ou por serem parcialmente cobertos, fatores que prejudicam tanto a ventilação quanto o acesso à luz do sol, gerando ambientes internos escuros e abafados. Na Figura 7, a janela basculante, que mede $0,8 \mathrm{~m} \times 0,8 \mathrm{~m}$, era a única fonte de iluminação e ventilação natural do dormitório, com área de $14,20 \mathrm{~m}^{2}$. Em um dormitório com tais dimensões, seria necessária uma janela basculante com área de $2,73 \mathrm{~m}^{2}$, caixilho de correr com veneziana ( 3 folhas) de $3,94 \mathrm{~m}^{2}$ e, por fim, janela de correr de vidro de $2,37 \mathrm{~m}^{2}$, dimensão bem superior aos $1,60 \mathrm{~m}^{2}$ de janela existente. 
Figura 5 - Casa 7, corredor lateral aberto

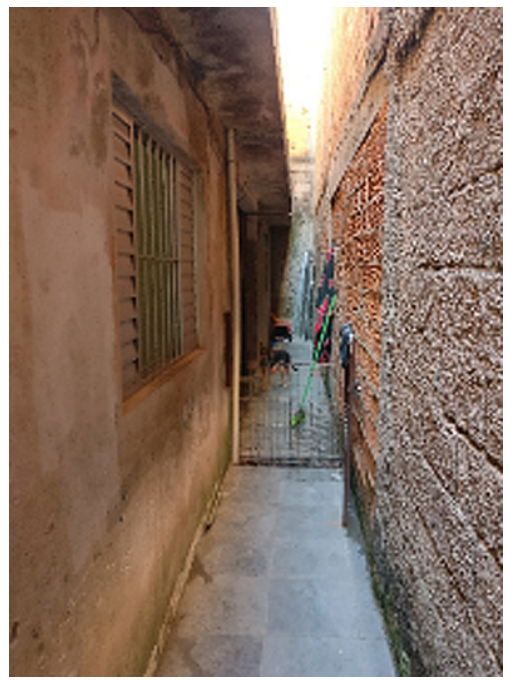

Fonte: arquivo pessoal.

Figura 7 - Casa 22,

caixilho muito menor que o necessário em dormitório

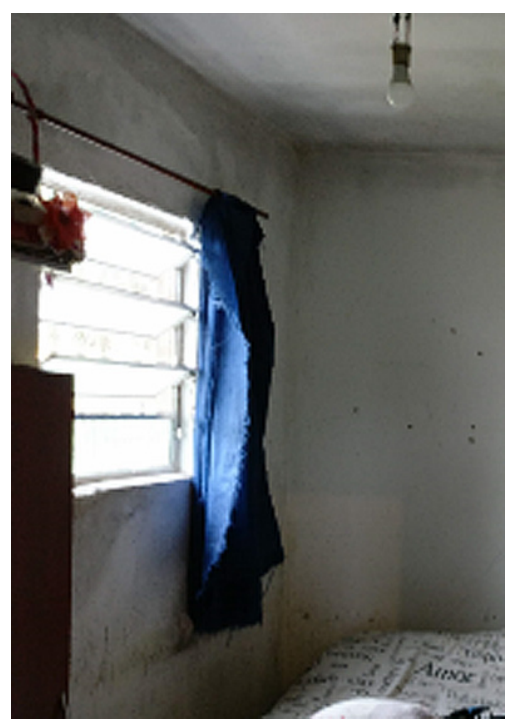

Fonte: arquivo pessoal.
Figura 6 - Casa 9,

corredor lateral estreito e semicoberto

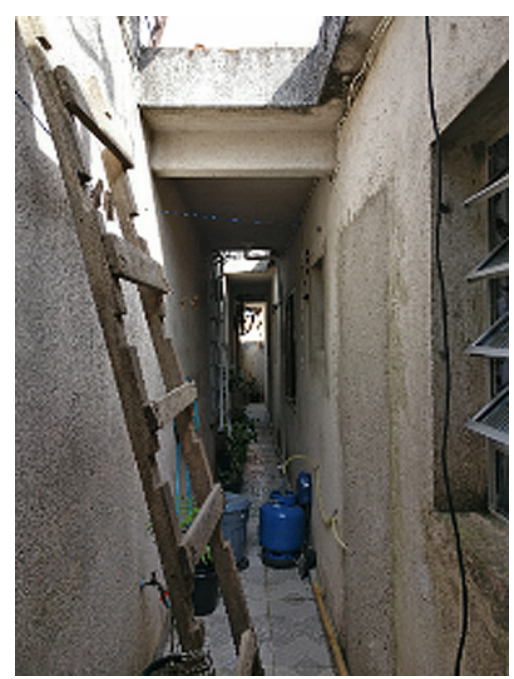

Fonte: arquivo pessoal.

Figura 8 - Casa 22,

a falta de espaço fez com que um corredor lateral fosse transformado em cozinha e área de serviço

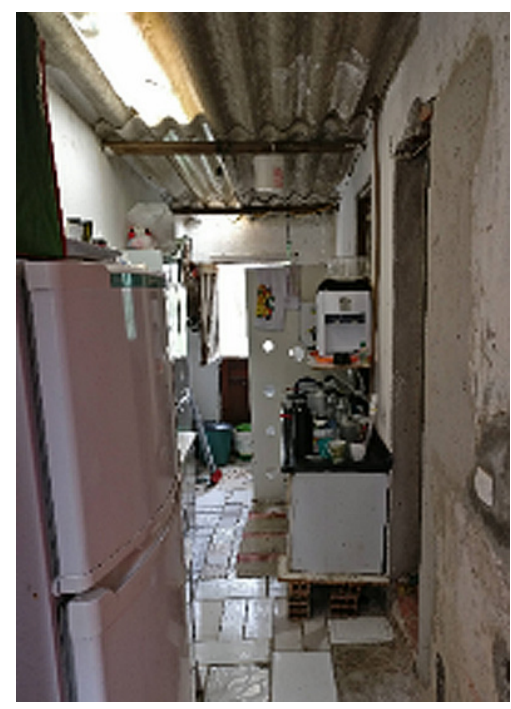

Fonte: arquivo pessoal. 
Figura 9 - Casa 18,

o telhado de fibrocimento na ampliação da casa deixa fenda de luz visível

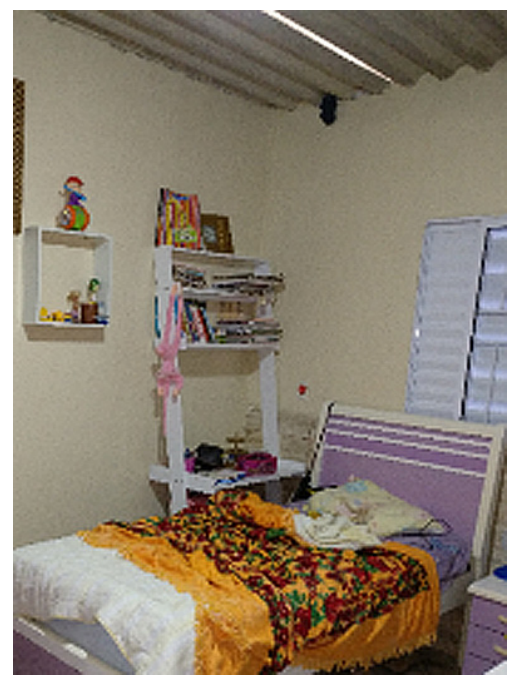

Fonte: arquivo pessoal.

Importante ressaltar que a ventilação natural na escala microclimática urbana depende basicamente da topografia, dos obstáculos, naturais ou não, da rugosidade e permeabilidade das edificações a alterações termodinâmicas, como evaporação, evapotranspiração, transferência de calor e emissão de poluentes. Sousa (2014) aponta que, quando o espaçamento entre as edificações é reduzido e o gabarito não tem diferenças representativas na altura, o que acontece no assentamento estudado, ocorre uma elevação do gradiente de ventilação, prejudicando a qualidade do ar em função da redução da taxa de renovação do ar.

Na Figura 8, o recuo externo foi coberto e incorporado à área da casa, deixando o ambiente escuro e sem ventilação. Na Figura 9, as telhas onduladas cobrem o segundo
Figura 10 - Casa 18 , mofo nas paredes e lajes persiste mesmo com a construção do segundo pavimento

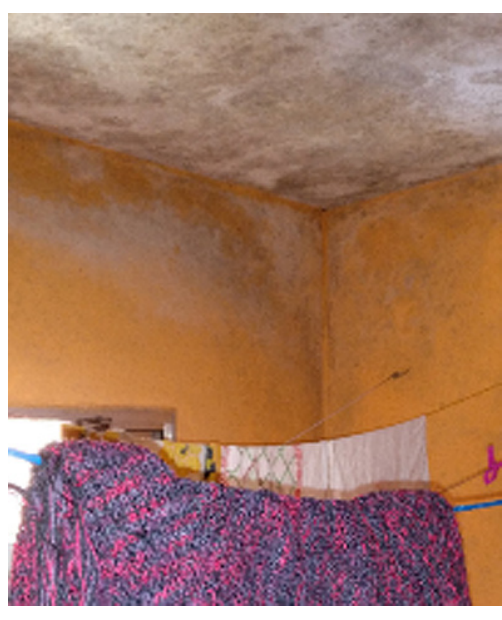

Fonte: arquivo pessoal. pavimento, criado para atender ao crescimento da família, mas a inclinação menor que o indicado pelos fabricantes de telhas, aliada à má instalação do material (fresta visível na imagem), acaba provocando infiltrações. Na Figura 10, o mofo persiste mesmo após a construção do segundo pavimento.

Com base nas análises anteriores, o Quadro 8 sintetiza os elementos construtivos que interferem no desempenho térmico das habitações, estipulando diretrizes para avaliar as construções. Para tanto, divide os elementos da envoltória em relação aos efeitos das temperaturas extremas. A influência do calor ficou decomposta em elementos da cobertura e o posicionamento das aberturas. Como as alvenarias empregadas são, em geral, adequadas à norma em relação ao calor, aliado ao sombreamento 
Quadro 8-Síntese dos elementos construtivos que prejudicam o desempenho térmico e a estanqueidade das casas pesquisadas

\begin{tabular}{|c|c|c|}
\hline Clima & Construção & Descrição \\
\hline \multirow{6}{*}{$\begin{array}{c}\text { Temperaturas } \\
\text { extremas }\end{array}$} & Laje sem telhado & $\begin{array}{l}\text { Como pode ser verificado no levantamento dos materiais e suas } \\
\text { características térmicas, lajes de concreto sem telhado não têm } \\
\text { desempenho dentro dos padrões da norma (NBR n. 15.220), podendo } \\
\text { resultar em superaquecimento do interior e maior consumo de } \\
\text { eletricidade (condicionamento de ar). }\end{array}$ \\
\hline & $\begin{array}{l}\text { Telhado de } \\
\text { fibrocimento }\end{array}$ & $\begin{array}{l}\text { O telhado de fibrocimento não tem desempenho dentro dos padrões da } \\
\text { norma (NBR n. 15.220), podendo resultar em superaquecimento e maior } \\
\text { consumo de eletricidade (condicionamento de ar). }\end{array}$ \\
\hline & $\begin{array}{l}\text { Janelas voltadas a } \\
\text { corredores estreitos }\end{array}$ & $\begin{array}{l}\text { A proximidade entre as casas e os muros de divisa prejudicam o fluxo de } \\
\text { ar, dificultando a renovação do ar interno. Essa proximidade prejudica } \\
\text { também a iluminação natural, que acaba sendo compensada com } \\
\text { iluminação artificial. }\end{array}$ \\
\hline & $\begin{array}{l}\text { Ambientes sem } \\
\text { abertura para o } \\
\text { exterior }\end{array}$ & $\begin{array}{l}\text { É comum encontrar ambientes com abertura para outros ambientes } \\
\text { internos, como quarto com janelas voltados para salas. Esse tipo de } \\
\text { estratégia dificulta a renovação do ar e o aproveitamento da ventilação } \\
\text { natural e iluminação natural. }\end{array}$ \\
\hline & $\begin{array}{l}\text { Cômodos sem } \\
\text { aberturas }\end{array}$ & $\begin{array}{l}\text { A ausência de abertura em um ambiente elimina a possibilidade de } \\
\text { ventilação e iluminação natural, incorrendo em maiores custos de } \\
\text { eletricidade para a iluminação e o condicionamento do ambiente. }\end{array}$ \\
\hline & $\begin{array}{l}\text { Aberturas na mesma } \\
\text { face }\end{array}$ & $\begin{array}{l}\text { A ventilação natural facilitada pelo posicionamento de aberturas em } \\
\text { fachadas opostas ou adjacentes. Quando a residência tem janelas em } \\
\text { uma só fachada a ventilação cruzada não acontece. }\end{array}$ \\
\hline
\end{tabular}

Fonte: elaborado pelas autoras.

resultante da proximidade entre as construções, determinou-se que as vedações verticais não seriam avaliadas neste estudo.

Em seguida, a Tabela 2 apresenta a matriz de avaliação, indicando que elementos construtivos das habitações pesquisadas estão mais suscetíveis aos efeitos do calor. É evidente que o maior problema das habitações são os aspectos relacionados às aberturas. Janelas mal posicionadas, voltadas para corredores laterais estreitos, ocorrem em 21 das 32 habitações pesquisadas. A segunda maior ocorrência, aberturas voltadas para ambientes internos, estão presentes em 16 habitações. 0 posicionamento, aliado ao dimensionamento insuficiente, resulta em problemas de conforto ambiental, como a falta de iluminação e ventilação natural.

Questões associadas às coberturas ineficientes são um fator secundário na matriz. Em cada um dos itens relativos à cobertura, ausência de impermeabilização, telhado de fibrocimento mal executado, laje sem telhado e telhado de fibrocimento como cobertura única aparecem, respectivamente, em quatro construções. De qualquer forma, 
Tabela 2 - Avaliação das 32 moradias mediante parâmetros estipulados no Quadro 2

\begin{tabular}{|c|c|c|c|c|c|c|}
\hline \multirow[b]{2}{*}{ Casa } & \multicolumn{6}{|c|}{ ONDAS DE CALOR } \\
\hline & $\begin{array}{l}\text { Laje sem } \\
\text { telhado }\end{array}$ & $\begin{array}{l}\text { Telhado de } \\
\text { fibrocimento }\end{array}$ & $\begin{array}{c}\text { Janelas voltadas } \\
\text { a corredores } \\
\text { estreitos }\end{array}$ & $\begin{array}{l}\text { Ambientes s/ } \\
\text { abertura para } \\
\text { o exterior }\end{array}$ & $\begin{array}{l}\text { Cômodos sem } \\
\text { aberturas }\end{array}$ & $\begin{array}{l}\text { Aberturas na } \\
\text { mesma face }\end{array}$ \\
\hline 1 & 1 & & & & & \\
\hline 2 & & & & 1 & & \\
\hline 3 & & & 1 & 1 & & \\
\hline 4 & & 1 & 1 & 1 & & \\
\hline 5 & & & 1 & 1 & & \\
\hline 6 & 1 & & & 1 & & \\
\hline 7 & & & 1 & 1 & & \\
\hline 8 & & 1 & 1 & & & 1 \\
\hline 9 & & & 1 & & & \\
\hline 10 & & & & & 1 & \\
\hline 11 & & & & 1 & 1 & \\
\hline 12 & & & & & & \\
\hline 13 & & & 1 & & & \\
\hline 14 & & & 1 & 1 & 1 & \\
\hline 15 & & & & & & \\
\hline 16 & & & 1 & 1 & & 1 \\
\hline 17 & & & & & & \\
\hline 18 & & 1 & 1 & & & \\
\hline 19 & & & 1 & 1 & & \\
\hline 20 & & 1 & 1 & & & \\
\hline 21 & & & & & & \\
\hline 22 & 1 & & & 1 & 1 & \\
\hline 23 & & & 1 & 1 & & \\
\hline 24 & & & 1 & & & 1 \\
\hline 25 & & & 1 & 1 & 1 & \\
\hline 26 & & & & & 1 & \\
\hline 27 & & & 1 & & & \\
\hline 28 & & & 1 & 1 & & \\
\hline 29 & & & 1 & 1 & 1 & \\
\hline 30 & & & 1 & 1 & 1 & \\
\hline 31 & 1 & & 1 & & & \\
\hline 32 & & & 1 & & & \\
\hline Totais & 4 & 4 & 21 & 16 & 8 & 3 \\
\hline
\end{tabular}

Legenda: o valor 1 foi atribuído aos elementos da matriz que podem ser encontrados nas moradias; as células sem valor apontam a inexistência deles. A linha "Totais" mostra o número de moradias nas quais ocorre cada um dos indicadores utilizados.

Fonte: elaborado pelas autoras a partir do levantamento de campo. 
a inadequação de características térmicas de todos os sistemas utilizados como cobertura é um agravante para o desconforto provocado pelo superaquecimento, que acaba não sendo considerado pela matriz, mas foi apontado nas nos Quadros 6 e 7.

Aspectos nos quais o calor afeta a construção são mais recorrentes, sejam eles relacionados às aberturas ou às coberturas. $\mathrm{A}$ ineficiência em manter o calor do lado externo das habitações faz com que $53 \%$ dos entrevistados reclamem do desconforto durante a aplicação do questionário, mesmo que as visitas tenham ocorrido predominantemente no outono e no inverno, provocando reflexos diretos no consumo energético.

No dia 3 de abril de 2019, por exemplo, foram feitas imagens termográficas da casa 4 (Figura 11). A temperatura externa do ar, no período entre $12 \mathrm{~h} 50$ e $13 \mathrm{~h} 45$, era de aproximadamente de $28^{\circ} \mathrm{C}$ e a umidade, $43 \%$, enquanto a temperatura da superfície das telhas alcançou cerca de 68으 (Figura 14), em partes da cobertura, e da parede interna, $37.8^{\circ} \mathrm{C}$. 0 atraso térmico da telha de fibrocimento é de 0,2 horas, ou seja, em 12 minutos o material começa a irradiar o calor para o interior da moradia.

Corroborando a análise, durante as visitas de campo, observou-se a permanência de luzes acesas durante o dia, fato que levou à verificação do consumo de eletricidade de 18 moradias do universo pesquisado, que forneceram suas contas de energia. A média de consumo energético dessas moradias é de 222 kWh mês, mesmo inseridas em tarifas com subsídios para a baixa renda, em que o custo do $k W h$ é de aproximadamente $R \$ 0,45^{18}$ (sem impostos), resultando em um custo mensal médio de energia superior a $\mathrm{R} \$ 100,00$.

Figura 11 - Montagem com fotos termográficas da casa 4
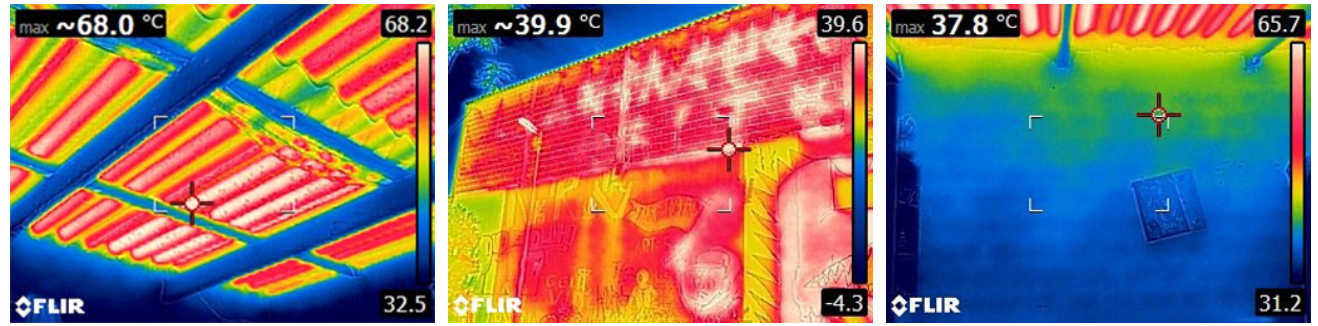

Legenda: a cobertura apresenta temperatura de $68^{\circ} \mathrm{C}$, a fachada mostra temperatura máxima de $39,9^{\circ} \mathrm{C}$ e a parede correspondente interna $37.8^{\circ} \mathrm{C}$.

Fonte: arquivo pessoal. 
Por fim, fica evidente que as habitações autoconstruídas analisadas apresentam problemas diversos que são exacerbados com o aumento do calor, um dos principais efeitos da mudança climática. A orientação técnica adequada poderia contribuir para minimizar os efeitos adversos do aumento da temperatura. Utilizando materiais e sistemas simples, de fácil aquisição e execução, como alvenaria em bloco cerâmico, laje pré-moldada e janelas de alumínio, uma autoconstrução com orientação técnica permitiria que esses materiais fossem aplicados de forma e posição adequadas, assim como combinados entre si para prover melhor conforto aos moradores e, consequentemente, melhor habitabilidade.

\section{Conclusões}

Alterações no clima é uma realidade enfrentada pelos assentamentos humanos. Como lidar com o problema é a chave para o sucesso de uma sociedade. Munir a população, especialmente a mais carente, de ferramentas para contornar problemas oriundos do clima é essencial para melhorar a sua qualidade de vida. A qualidade das habitações, configuradas como abrigo eficiente contra as intempéries, é de suma importância e um dos mecanismos necessários para garantir o desenvolvimento sustentável.

Esta pesquisa buscou identificar os elementos das envoltórias de habitações autoconstruídas que se relacionam com a elevação das temperaturas sob dois pontos de vista: questões relativas ao projeto, ou seja, posicionamento de aberturas e implantação e recuos, e desempenho térmico dos elementos que compõem coberturas e vedações. Cobertura, vedações e aberturas são elementos que intermedeiam a relação do interior com o exterior, sendo a linha de frente reativa ou passiva perante o clima.

Em relação às aberturas, o posicionamento e o dimensionamento das aberturas são problemas recorrentes nas moradias analisadas, que se aliam à ausência de orientação correta da habitação em relação ao sol e à implantação adequada no terreno, contribuindo para parte dos problemas levantados. Os sistemas utilizados, como coberturas das casas avaliadas, encontram-se em desacordo com as normas vigentes, e o calor transmitido impacta na sua temperatura interna e no seu consumo energético, trazendo consequências à saúde, à produtividade e à renda dos moradores.

Entender a relação entre o clima e a construção precária pode contribuir para elucidar o quanto o uso de materiais inadequados ou a ausência de auxílio técnico na construção e/ou melhoria habitacional prejudicam a qualidade de vida dos moradores. A carência de auxílio técnico para a concepção das habitações e execução das obras, aliada à falta de recursos financeiros dos moradores, leva a soluções inadequadas de construção, agravadas pelas características do clima local, prejudicando sua habitabilidade. 0 uso inadequado de materiais ou a ausência de um desenho da habitação que posicione as aberturas e fachadas de forma a maximizar o aproveitamento do sol e da ventilação natural, ou seja, a falta de projeto, proporcionam ambientes internos desconfortáveis.

Muitas vezes, para compensar falhas da envoltória, os moradores optam pela utilização de aparelhos mecânicos (ventiladores e climatizadores) que têm alto consumo de energia e 
que não necessariamente os protegem do calor, mas, sim, contribuem para comprometer parte do seu orçamento, aumentando sua vulnerabilidade socioeconômica. As ações acontecem no efeito, e não sobre a causa.

As técnicas e os materiais disponíveis para os moradores de autoconstruções não atendem às necessidades mínimas de conforto térmico e eficiência energética, e isso compromete a capacidade do morador de se adaptar ao clima atual. 0 problema nem tanto é do material em si, mas como e onde ele é empregado, aspectos que denotam a carência de orientação técnica da população que realiza a autoconstrução.

Como recomendação, reforça-se a necessidade de políticas públicas específicas que contribuam para munir a população de baixa renda de orientações técnicas voltadas para melhorar a qualidade da autoconstrução em um contexto de mudança climática. A Assistência Técnica de Interesse Social, com a participação de arquitetos e engenheiros, é um importante instrumento legal que as cidades brasileiras dispõem, desde 2008, voltado para orientar a autoconstrução. Uma vez adotada, poderá contribuir para minimizar os efeitos do calor, produto da mudança climática, tanto em situações como apresentadas neste estudo de caso, quanto em situações mais complexas de extrema vulnerabilidade. Nesse âmbito, reforça-se a necessidade de políticas públicas específicas para colocar em prática os preceitos desse instrumento e a conscientização dos profissionais envolvidos para contribuir, efetivamente, com a população de baixa renda.

\section{[I] https://orcid.org/0000-0003-3857-0853}

Universidade Presbiteriana Mackenzie, Faculdade de Arquitetura e Urbanismo, Programa de Pós-Graduação em Arquitetura e Urbanismo. São Paulo, SP/Brasil.

criscaselli@gmail.com

\section{[II] https://orcid.org/0000-0001-7538-2136}

Universidade Presbiteriana Mackenzie, Faculdade de Arquitetura e Urbanismo, Programa de Pós-Graduação em Arquitetura e Urbanismo. São Paulo, SP/Brasil.

angelica.alvim@mackenzie.br

\section{Agradecimentos}

À Fundação de Amparo à Pesquisa do Estado de São Paulo (Fapesp), que financiou a pesquisa que deu origem ao artigo científico, número do processo 2017/01781-7, com supervisão da professora doutora Angélica Aparecida Tanus Benatti Alvim. Este trabalho insere-se em pesquisas lideradas pela supervisora que contam com o apoio do Programa de Excelência da Capes, CNPq e Fundo MackPesquisa. 


\section{Notas}

(1) Segundo relatório World Urbanization Prospects (United Nations, 2018), em 2018 a população urbana mundial representava 55,3\% na América Latina; $80,7 \%$ no Caribe; e $87 \%$ no Brasil.

(2) A população urbana ultrapassou, em meados de 2019, a marca de 7,7 bilhões de pessoas (United Nations, 2019).

(3) A pesquisa "Retrofit verde como forma de mitigar os efeitos das mudanças climáticas em assentamentos precários em áreas de mananciais de São Paulo" foi desenvolvida, entre 2017 e 2019, com o apoio da Fapesp, no Programa de Pós-graduação em Arquitetura e Urbanismo da Universidade Presbiteriana Mackenzie, sob supervisão da professora Angélica Benatti Alvim.

(4) A NBR 15575 aponta valores mínimos de desempenho térmico, mas isso não significa que a habitação seja confortável para todos, garante, apenas, que o usuário esteja exposto a condições iguais ou melhores às do ambiente externo, evitando, ainda, mais irregularidades nas construções (Brito et al., 2017).

(5) Pesquisa disponível em: http://www.caubr.gov.br/pesquisa2015/. Acessada em: 30 out 2015.

(6) O CAU pretende alocar no mínimo $2 \%$ do total das receitas de arrecadação do conselho para ações estratégicas de Assistência Técnica em Habitações de Interesse Social (Athis). Informações disponíveis em: http://www.caubr.gov.br/56a-plenaria-cau-destinara-recursos-para-projetos-eobras-de-assistencia-tecnica/; acesso em: 13 nov 2018.

(7) O questionário passou pelo Comitê de Ética da Universidade Presbiteriana Mackenzie, sendo aprovado em 15 de maio de 2018, por meio do parecer número 2.656.035. As entrevistas foram realizadas entre 2018 e 2019.

(8) A NBR 15.220 aponta recomendações relativas ao desempenho térmico de habitações unifamiliares de interesse social e estabelece um Zoneamento Bioclimático Brasileiro. Informações disponíveis em: http://projeteee.mma.gov.br/glossario/nbr-15220/; acesso em: 21 maio 2020.

(9) A cidade de São Paulo pertence à Zona 3 do Zoneamento Bioclimático Brasileiro, apresentado na NBR 15.220.

(10) O site Projeteee 10 - a primeira plataforma nacional que agrupa soluções para um projeto de edifício eficiente, com intuito de dar continuidade ao trabalho desenvolvido pelo Procel/Eletrobrás e pela Universidade Federal de Santa Catarina - é uma ferramenta pública desenvolvida pelo Laboratório de Eficiência Energética em Edificações - LabEEE/UFSC, que permite a manipulação da carta solar e da rosa dos ventos com dados de cidades selecionadas. Disponível em: http:// projeteee.mma.gov.br/componentes-construtivos/; acesso em: 14 out 2019.

(11) O Teorema Central do Limite indica que uma sucessão de $X$ variáveis, independentes e identicamente distribuídas, converge para uma distribuição normal sempre que o tamanho $X$ for suficientemente grande. Ou seja, para distribuições amostrais, o número $X$ de elementos deve ser igual ou superior a 30 (Alves, 2016, p. 12). 
(12) O IPVS (Índice Paulista de Vulnerabilidade Social) é um importante instrumento para levantar áreas que concentram população em situação de fragilidade, e que devam ser alvo prioritário de políticas públicas. O IPVS considera a renda, a composição familiar, as condições de saúde e o acesso a serviços médicos, assim como o acesso e a qualidade do sistema educacional, a empregabilidade com remuneração adequada e garantias legais principalmente no que tange à moradia (Seade, 2010, p. 8).

(13) Ocupação desprovida total ou parcialmente de infraestrutura de saneamento ambiental, para a qual o Poder Público deverá promover programas de recuperação urbana e ambiental. Para detalhamento, consultar Alvim (2011) e França e Barda (2012).

(14) O projeto do Parque foi retomado a partir de 2018 com obras no trecho correspondente ao Loteamento Cantinho do Céu, região de maior vulnerabilidade.

(15) Josiane Ribeiro, líder do Cantinho do Céu, e Adolfo "Ferrugem", da ONG Meninos da Billings, foram essenciais para o desenvolvimento da pesquisa de campo. Eles ajudaram a fazer a ponte entre as pesquisadoras e a comunidade, para quebrar as barreiras de desconfiança da população.

(16) Conforto térmico depende dos mecanismos de dissipação de calor do corpo humano e de quatro condições ambientais: temperatura do ar, umidade relativa do ar, temperatura radiante média e movimento do ar (ventilação) (Lechner, 2009).

(17) É importante ressaltar que, em função da imprecisão gerada pela deficiência de dados climáticos, já existem propostas para rever essa divisão (Amorim e Carlo, 2017).

(18) Dados do site da Enel, disponíveis em: https://www.eneldistribuicaosp.com.br/para-sua-casa/ tarifa-de-energia-eletrica; acesso em: 29 jul 2019. A tributação do PIS e Cofins é variável e o ICMS é na região de 12\%, sendo possível estimar apenas parte do valor final da conta de luz.

\section{Referências}

ABNT-NBR n. 15.220 (2005). Desempenho térmico de edificações. Parte 3: Zoneamento bioclimático brasileiro e diretrizes construtivas para habitações unifamiliares de interesse social. Associação Brasileira de Normas Técnicas. Rio de Janeiro, p. 30.

ALVES, J. (2016). Teorema central do limite compreendendo e aplicando. Dissertação de Mestrado. Cruz das Almas, Universidade Federal do Recôncavo da Bahia.

ALVIM, A. (2011). Direito à cidade e ao ambiente na metrópole contemporânea. Disponível em: https:// www.vitruvius.com.br/revistas/read/arquitextos/12.135/4015. Acesso em: 4 maio 2020.

AMORIM, A. C.; CARLO, J. C. (2017). Análise das propostas de revisão do zoneamento bioclimático brasileiro: estudo de caso de Colatina, ES. Ambiente Construído. Porto Alegre, v. 17, n. 1, pp. 373-391.

APOLLARO, C.; ALVIM, A. B. (2017). Planejamento urbano para a adaptação de cidades frente à mudança climática - Uma análise sobre o Plano Diretor Estratégico do Município de São Paulo. Thésis. Rio de Janeiro, v. 2, n. 4, pp. 118-137. 
BALTAZAR, R. D. S. (2012). A permanência da autoconstrução: um estudo de sua prática no município de Vargem Grande Paulista. Dissertação de Mestrado. São Paulo, Universidade de São Paulo.

BRASIL (2007). Plano Nacional Sobre Mudança do Clima - PNMC - Comitê Interministerial Sobre Mudança do Clima. Decreto n. 6.263, de 21 de novembro de 2007. Disponível em: https:// www.mma.gov.br/estruturas/smcq_climaticas/_arquivos/plano_nacional_mudanca_clima.pdf. Acesso em: 20 maio 2020.

(2008). Lei n. No 11.888, de 24 de dezembro de 2008. Assegura às famílias de baixa renda assistência técnica pública e gratuita para o projeto e a construção de habitação de interesse social. Brasília.

BRITO, A. C.; SAlES, E. M.; VITTORINO, F.; AQUILINO, M. M.; AKUTSU, M. (2017). "Proposta de Procedimentos para Avaliação do Desempenho Térmico de Edificações (NBR 15.575 e SiNAT - método detalhado". In: FABRICIO, M. M.; BRITO, A. C.; VITTORINO, F. (2017). Avaliação do desempenho de tecnologias construtivas inovadoras: conforto ambiental, durabilidade e pós ocupação. Porto Alegre, Antac.

CALDEIRA, T. (2017). Peripheral urbanization: Autoconstruction, transversal logics, and politics in cities of the global south. Environment and Planning D: Society and Space, v. 35, pp. 3-20.

CAU-BR (2015). O maior diagnóstico sobre arquitetura e urbanismo já feito no Brasil. Disponível em: http://www.caubr.gov.br/pesquisa2015/. Acesso em: 24 maio 2015.

COELHO, T. D. C. C.; GOMES, C. E. M.; DORNELLES, K. A. (2017). Desempenho térmico e absortância solar de telhas de fibrocimento sem amianto submetidas a diferentes processos de envelhecimento natural. Ambiente Construído. Porto Alegre, v. 17, n. 1, pp. 147-161.

ELETROBRAS/PROCEL (2015). Manual para Aplicação do RTQ-R. Disponível em: http://www. pbeedifica.com.br/sites/default/files/projetos/etiquetagem/residencial/downloads/Manual_ de_aplica\%C3\%A7\%C3\%A3o_do_\%20RTQ-R-v01.pdf. Acesso em: 3 mar 2018.

EPA (2017). Climate Change and Heat Islands. United States Environmental Protection Agency. [Online] United States government, 13 de abril. Disponível em: https://www.epa.gov/heat-islands/ climate-change-and-heat-islands. Acesso em: 21 mar 2018.

FIELD, C. B.; BARROS, V.; STOCKER, T. F.; DAHE, Q. (orgs.) (2012). Managing the Risks of Extreme Events and Disasters to Advance Climate Change Adaptation (SREX). Nova York, Cambridge University Press.

FRANÇA, E.; BARDA, M. (orgs.) (2012). Entre o céu e a água: o Cantinho do Céu. São Paulo, HABI Superintendência de Habitação Popular.

HALLEGATTE, S. et al. (2016). Schock Waves. Managing the Impacts of Climate Change on poverty. Washington, World Bank.

KHODAY, K.; ALI, W. (2018). Climate Change and the Rise of Poverty. United Nations Development Programme, 19 dezembro. Disponível em: <http://www.undp.org/content/undp/en/home/ blog/2018/Climate_Change_and_the_Rise_of_Poverty.html>. Acesso em: 15 jun 2018.

LECHNER, N. (2009). Heating, cooling, lighting. Sustainable Design Methods for Architects. New Jersey, John Wiley \& Sons. 
LÖW, J. L.; NADER, G. (2019). Esfera microclimática: ventilação, conforto e moradia. Revista IPT Tecnologia e Inovação. São Paulo v. 2, n. 10. Disponível em: http://revista.ipt.br/index.php/ revistaIPT/article/view/75/83. Acesso em: 18 maio 2020.

MARICATO, E. (1979). “Causas e consequências da autoconstrução na grande SP”. In: MARICATO, E. (org.). A produção capitalista da casa (e da cidade) no Brasil Industrial. São Paulo, Alfa Ômega.

MATSUnAGA, M. K. (2015). Cantinho do Céu. Dissertação de Mestrado. São Paulo, Universidade São Paulo.

MCTARNAGHAN, S. et al. (2016). Revisão da literatura sobre habitação na América Latina e no Caribe. Disponível em: https://www.urban.org/sites/default/files/global_housing_research_ initiative_-_portuguese.pdf. Acesso em: set 2018.

MIRANDA, M. E. (2003). Meio ambiente e habitação popular: o caso do Cantinho do Céu. Tese de Doutorado. São Paulo, Universidade de São Paulo.

NOBRE, C. et al. (2011). Vulnerabilidade das megacidades brasileiras às mudanças climáticas: Região Metropolitana de São Paulo. Disponível em: https://www.nepo.unicamp.br/publicacoes/livros/ megacidades/megacidades_RMSP.pdf. Acesso em: 20 jun 2017.

NOBRE, C.; REID, J.; VEIGA, A. (2012). Fundamentos científicos das mudanças climáticas. São José dos Campos, Inpe.

OLIVEIRA, R. F.; ALVES, J. W. S. (2011). Mudanças climáticas globais no Estado de São Paulo. São Paulo, SMA.

PLANO MUNICIPAL DA HABITAÇÃO (2010). PMH 2009-2024. São Paulo, Prefeitura de São Paulo Habitação.

ROAF, S.; CRICHTON, D.; NICOL, F. (2009). Adapting Buildings and Cities for Climate Change: a 21st Century Survival Guide. Nova York, Routledge.

SAMPAIO, M. R. (1990). A casa brasileira. Revista USP. São Paulo, n. 5, pp. 113-116.

SÃO PAULO - PREFEITURA MUNICIPAL DE SÃO PAULO (2019). GeoSampa. Disponível em: <http:// geosampa.prefeitura.sp.gov.br/PaginasPublicas/_SBC.aspx>. Acesso em: 4 jun 2019.

SEADE (2010). Índice Paulista de Vulnerabilidade Social. São Paulo. Disponível em: http://catalogo. governoaberto.sp.gov.br/dataset/21-ipvs-indice-paulista-de-vulnerabilidade-social. Acesso em: 24 jul 2018.

SOUSA, J. P. M. (2014). Influência da Forma Urbana na Ventilação Natural: um estudo de caso no Cais José Estelita, Recife. Dissertação de mestrado. Recife, Universidade Federal de Pernambuco.

UN-HABITAT (2003). The challenge of slums: global report on human settlements. Disponível em: https://www.emerald.com/insight/content/doi/10.1108/meq.2004.15.3.337.3/full/html. Acesso em: 15 set 2019.

UNITED NATIONS (2015). The Millennium Development Goals Report. Disponível em: https://www. un.org/millenniumgoals/2015_MDG_Report/pdf/MDG\%202015\%20rev\%20(July\%201).pdf. Acesso em: 20 set 2019.

(2018). World Urbanization Prospects. Disponível em: https://esa.un.org/unpd/wup/ Download/. Acesso em: 10 out 2019. 
UNITED NATIONS (2019). Population Division. World Population Prospects 2019: Highlights. Disponível em: https://population.un.org/wpp/. Acesso em: 21 out 2019.

WHO - WORLD HEALTH ORGANIZATION (2018). Housing and health guidelines. Geneva. Disponível em: https://apps.who.int/iris/bitstream/handle/10665/276001/9789241550376-eng.pdf. Acesso em: 14 out 2019.

Texto recebido em 23/set/2019

Texto aprovado em 5/nov/2019 